\title{
A COMPARISON OF SINGLE AND DOUBLE LIP RIM SEAL GEOMETRIES
}

\author{
Svilen S. Savov \\ Whittle Laboratory, \\ Dept. of Engineering, \\ University of Cambridge, \\ CB3 ODY, UK \\ sss44@cam.ac.uk
}

\author{
Nicholas R. Atkins \\ Whittle Laboratory, \\ Dept. of Engineering, \\ University of Cambridge, \\ CB3 0DY, UK \\ nra27@cam.ac.uk
}

\author{
Sumiu Uchida \\ Technology and Innovation HQ \\ Mitsubishi Heavy Industries Ltd., \\ 5-717-1 Fukahori-machi, Nagasaki \\ 851-0392, Japan \\ sumiu_uchida@mhi.co.jp
}

\begin{abstract}
The effect of purge flow, engine-like blade pressure field and mainstream flow coefficient are studied experimentally for a single and double lip rim seal. Compared to the single lip, the double lip seal requires less purge flow for similar levels of cavity seal effectiveness. Unlike the double lip seal, the single lip seal is sensitive to overall Reynolds number, the addition of a simulated blade pressure field and large scale non-uniform ingestion. In the case of both seals, unsteady pressure variations attributed to shear layer interaction between the mainstream and rim seal flows appear to be important for ingestion at off-design flow coefficients.

The double lip seal has both a weaker vane pressure field in the rim seal cavity and a smaller difference in seal effectiveness across the lower lip than the single lip seal. As a result, the double lip seal is less sensitive in the rotor-stator cavity to changes in shear layer interaction and the effects of large scale circumferentially non-uniform ingestion. However, the reduced flow rate through the double lip seal means that the outer lip has increased sensitivity to shear layer interactions.

Overall, it is shown that seal performance is driven by both the vane/blade pressure field and the gradient in seal effectiveness across the inner lip. This implies that accurate representation of both, the pressure field and the mixing due to shear layer interaction would be necessary for more reliable modelling.
\end{abstract}

\section{INTRODUCTION}

In industrial and aero gas turbines, purge air is bled from the compressor and fed into the turbine rotor-stator disk cavities. This air cools the cavity and reduces hot gas ingestion. Reliable cooling of the rotor-stator cavity prevents mechanical failure due to thermal damage. From an engine designer's point of view, minimising purge flow for engine efficiency must be balanced against the probability of unexpected thermal degradation and seal life. At present there is a lack of reliable methods to predict the amount of purge flow required for acceptable cavity temperatures without engine tests.

The overarching research question of this work is to find the necessary and sufficient requirements for the reliable design of rotor-stator purge systems through modelling. A firm answer remains elusive. Progress is made in this experimental work using a high density of instrumentation with engine style geometry

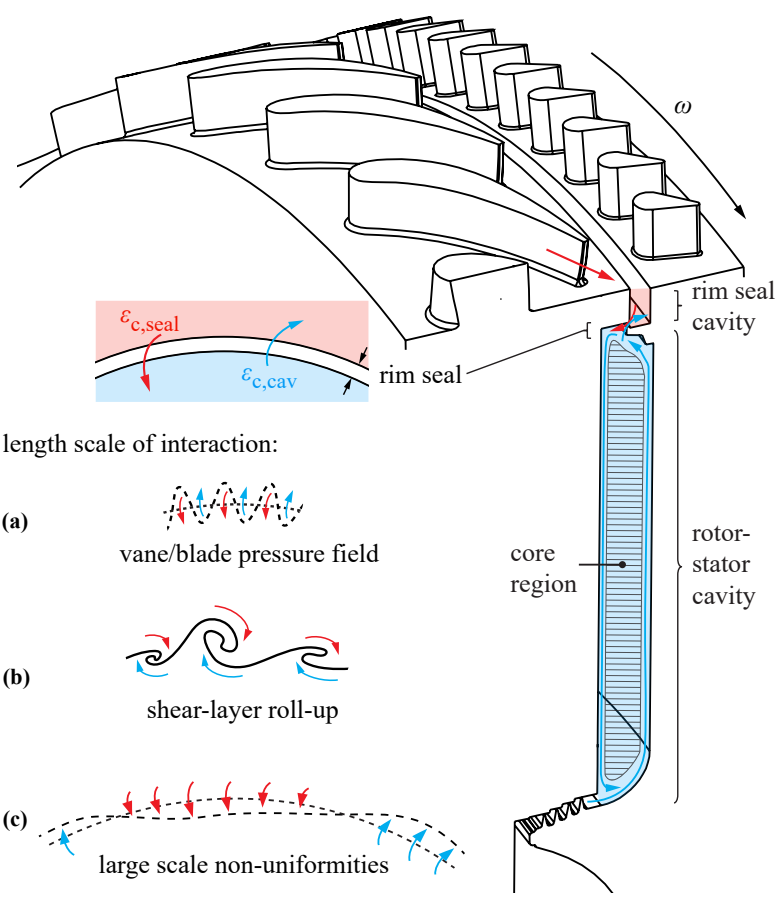

FIGURE 1. Test rig schematic and potential ingress/egress patterns.

and dimensionless conditions approaching engine values. The most important result is that the interactions between the mainstream and cavity/rim seal flows lead to ingestion mechanisms with a range of length scales. Figure 1 illustrates three examples of mainstream-cavity interaction which will be discussed.

The rotor-stator cavity is characterized by viscous pumping on the rotor, entrainment on the stator and the presence of a rotating core region, stiffened by the dominant Coriolis forces. As a result, radial outflow/inflow is confined to the boundary layers where viscous forces dominate. External to the rim seal, the mainstream flow has a high swirl component and a nonuniform pressure field due to the vanes and blades.

It is well known (as discussed in the background section below) that the vane pressure field leads to steady state regions of ingress and egress on the scale of the vane pitch (fig. 1, a). Previous CFD studies have shown instabilities in the shear layer between the rim seal and mainstream flow with larger length scales than vane/blade pitch (fig. 1, b). This paper shows the first experimental evidence of such instabilities and their effect 
on mixing in the rim seal. Circumferential measurements show that ingestion may also be affected by even larger scale nonuniformities in the rim seal-mainstream flow interaction (fig. 1, c). The effects of these non-uniformities appear to be exacerbated by the rotationally dominated cavity flow.

This paper compares two rim seal geometries - a single lip and a double lip rim seal. Measurements and discussion of their sensitivities to: purge flow rate; simulated engine blade pressure field; large scale non-uniform ingestion; and changes in mainstream flow coefficient (off-design disk speed) are presented.

Compared to the single lip, the double lip seal requires less purge flow for similar levels of cavity seal effectiveness. The double lip seal has both a weaker vane pressure field in the rim seal cavity and a smaller difference in seal effectiveness across the lower lip. The smaller gradient across the lower lip of the double lip seal suggests that it is less sensitive in the rotor-stator cavity to mainstream-cavity interactions across all length scales. Unlike the double lip seal, the single lip seal is sensitive to overall Reynolds number, the addition of a simulated blade pressure field and large-scale non-uniform ingestion.

\section{BACKGROUND}

Rotor-stator cavity ingress is generally grouped into two categories - rotationally induced (entrainment by the recirculating cavity flow) and externally induced (driven by the mainstream pressure field). Early studies by Bayley and Owen [1], Phadke and Owen [2] [3] and Bhavani et al. [4] without a mainstream found that ingress depends on seal geometry and rotational Reynolds number (rotational ingress). Studies by Abe et al. [5], Phadke and Owen [6] [7] and Graber et al. [8] showed that with a mainstream, the minimum purge flow to prevent ingress depends more on the external flow field (externally induced ingress dominates).

Pressure Asymmetry Phadke and Owen [7] investigated the effect of non-axisymmetric pressure distributions on ingestion and found that the minimum amount of purge necessary to prevent ingress increases with increasing peak-to-peak pressure asymmetry in the external flow dominated regime. With time, test facilities have started to feature more engine realistic main path geometry. Studies such as by Dadkhah et al. [9] and Bohn et al. [10] demonstrated that the vane pressure field modulates the level of ingress of mainstream gas. The circumferential pressure asymmetry introduced by vanes means that alternating regions of ingress and egress can occur around the rotor-stator cavity. Where the pressure at the rim seal is higher than the cavity mean, ingress occurs and where it is lower, egress occurs. Evidence of such regions was shown through velocimetry measurements by Zhou et al. [11].

Blade Pressure Field The rotor blades also generate a pressure field. Green and Turner [12] studied the effect of blades on a simple axial clearance seal. They found the presence of rotor blades increases the seal effectiveness measured in the rotorstator cavity at all purge flow rates. Bohn et al. [13] investigated the addition of blades for an axial clearance rim seal similar to the one studied by Green and Turner, as well as an open rotorstator cavity. For the axial clearance seal, the authors confirmed the findings of Green and Turner. However, for the open rotor- stator cavity, Bohn et al. showed that the addition of blades reduces the seal effectiveness. Most current test facilities feature both stator vanes and some type of rotor blades - e.g. Bohn et al. [14], Gentilhomme et al. [15], Sangan et al. [16] and Balasubramanian et al. [17].

1-D Modelling Numerous empirical ingestion models have been proposed. The majority model ingress and egress through the rim seal as an orifice flow moderated by empirical discharge coefficients found by fitting to experimental data for a given seal. Amongst others Phadke and Owen [7], Chew et al. [18], Reichert and Leiser [19], Bohn and Wolff [20], Scanlon et al. [21], Johnson et al. [22], Owen et al. [23] all present models of this type. As these models can only describe the variation in seal performance with dimensionless flow rate for a seal which has been experimentally characterised, they do not allow prediction. Notwithstanding, the models represent the state of the art and are yet to be superseded.

Numerical Modelling and Unsteadiness Early CFD modelling of cavity purge flow focused on small sector Reynolds Averaged Navier-Stokes (RANS) studies. This type of model appears to under-predict ingestion [24] [11].

Advances in computational power have enabled full annulus Unsteady RANS (URANS) simulations (e.g. Cao et al. [25], Jakoby et al. [26], Wang et al. [27] and Mirzamoghadam et al. [28]) which show improved results compared to experimental data. These studies all show large scale flow structures (at frequencies unrelated to blade passing) in the rotor-stator cavity which provide a mechanism for increased levels of ingress. The presence of such structures is inherently restricted in periodic small sector studies. The number of vortex pairs appear to be geometry related - different numbers exist across the different studies and cavity geometries. Some experimental evidence for such large scale cavity unsteadiness has been provided in open literature (e.g. Jakoby et al. [26], Cao et al. [25], Roy et al. [29] and Mirzamoghadam et al. [28]). However, the existence of a clear link between unsteadiness (coherent or otherwise) and ingestion remains an open research question.

Several computational studies have also reported the presence of instabilities in the rim seal cavity. Boudet et al. [30] presented results from a single passage URANS study, where pressure probes showed the presence of several frequencies below blade passing. O'Mahoney et al. [24] extended the study by Boudet et al. by performing Large Eddy Simulations (LES) on the same geometry. For comparison, the LES mesh was also run in URANS. While in the URANS simulations distinct frequency peaks are observed, peaks are seen over a greater range of frequencies in the vicinity of the dominant modes in the LES simulations. As pointed out by the authors, the larger eddy viscosity term in URANS compared to LES could give the vortical structures greater stability. Comparing numerical and experimental data, O'Mahoney et al. showed that the LES simulations predicted performance closer to measurements. However, it was pointed out that significant discrepancies remain relative to experiment.

Chilla et al. [31] performed URANS CFD modelling of the Rolls-Royce Generic Turbine Rig. They showed that at typical engine conditions the difference in tangential velocity between the mainstream and rim seal flow results in shear layer 
roll-up (i.e. a Kelvin-Helmholtz type instability). It was found that by independently increasing the rim seal mass flow rate and increasing the rim seal tangential velocity, the flow field is stabilised. Unsteady pressure probes in the relative frame of motion showed a spike in amplitude at a frequency below stator vane passing and surrounded by a band of elevated activity. The authors noted that the spike frequency shifts with rim seal shape.

Rabs et al. [32] performed unsteady simulations of a 1.5 stage turbine test rig with and without blades. The authors found that the introduction of a blade pressure field suppresses the Kelvin-Helmholtz type instabilities. However, it was noted that at sufficiently large rim seal flow rates and in the presence of blades, instabilities could still occur. The above findings are confirmed experimentally in the present work and it is shown that increased ingress can be driven by higher shear.

Seal Eccentricity The impact of seal axial movement and various overlap shapes has been studied (e.g. Popovic and Hodson [33] [34], Mirzamoghadam et al. [35]). However, industrial gas turbine shafts are long relative to rim seal clearances, so static radial deflections, or eccentricity, are also a source of uncertainty during engine operation. To the authors' knowledge there are no published experimental studies in open literature on the effect of seal eccentricity on rim seal ingestion. However, eccentricity has been investigated computationally using steady CFD simulations by Lowry and Keeton [36] in the late 1980's and Guo et al. [37] in the early 1990's. Both research teams found that eccentricity leads to worse seal performance. In their simulations, Guo et al. noted a spatial phase lag between the minimum seal effectiveness on the stator near the rim seal and the maximum seal clearance. The authors also noted a more pronounced peak in temperature at the stator vane root than at the rotor blade root and a phase difference between the maximum temperature at the two points. The lower temperature on the rotor is attributed to mixing with the recirculating air which spreads the temperature variation over a larger domain. The differences in phase were attributed to the swirl components of the flow in the rotor-stator cavity.

The next section presents an overview of the experimental setup and test conditions in the present work.

\section{TEST GEOMETRY, CONDITIONS AND SETUP}

The geometry used in this work is a scaled and truncated engine stage. The test rig is approximately $50 \%$ of the engine scale, with a rotor disk radius, $r_{\mathrm{b}}$, of $597.8 \mathrm{~mm}$. The rig mainstream is truncated to $32.5 \%$ of the equivalent engine blade span. The adaption of the engine geometry to the rig was done using steady CFD predictions in Turbostream [38] of the main annulus only. The grid used is a 1.5 Million cell 'sheared-H' mesh. It has a non-reflecting mixing plane between the vane and blade at the axial location of the intersection of the static rim seal and the hub. The vane and blade pressure field are discussed in more detail below.

\section{Vane and Blade Pressure Field Validation}

To simulate the engine representative pressure field, the rig features 40 vanes and 96 removable tear-drop shaped blockage elements. Although not designed to turn the flow or extract work, they are referred to as blades in this paper for brevity. Engine like velocity triangles at the rim seal are achieved by scaling the disk speed to match the engine flow coefficient, $\phi$.

The correspondence between the engine and rig pressure fields is summarised in fig. 2. The engine case uses typical engine boundary conditions, and the rig case uses measured inlet stagnation and vane exit static measurements. The stubby blockage elements are shown overlayed onto the engine blades in the central cartoon. Predicted vane and blade pressure coefficients are plotted against vane pitch for a single vane (a) and single blade (b).

The vane pressure coefficient, $C_{P}$, shown in plot (a) is based on the inlet stagnation pressure and the isentropic dynamic head at vane exit. The data plotted corresponds to a location on the hub at $2 \%$ of axial chord, $c_{x}$, downstream of the vane trailing edge.

The blade pressure coefficient shown in plot (b) is based on the blade relative frame inlet stagnation pressure and dynamic head. It is plotted at an axial location just downstream of the mixing plane, corresponding to the stator edge of the single lip rim seal. The radial location is at $40 \%$ of rig span, which is equivalent to $12.5 \%$ of engine span.

The shape and peak-to-peak variation of the engine pressure coefficient is well simulated by the truncated vanes and stubby blades. The magnitude of the peak-to-peak variation is lower in the rig case, mainly due to the truncation.

Fig. 2 (a) also presents pressure coefficient data measured on the hub at the location indicated in the cartoon. There is good agreement between the computed and measured data at a vane exit isentropic Mach number, $M_{\mathrm{is}}$, of 0.64 showing that the vanes are operating as intended. Measurements at $M_{\mathrm{is}}=0.20$ are also shown. There is close agreement between the data at the two vane operating conditions demonstrating that the effect of compressibility is small.

Next, the mainstream inlet and exit setup is discussed.

\section{Inlet and Exit Flow}

Air is drawn from atmosphere through a radial bell-mouth inlet with a contraction ratio of 13 . Upstream of the stator vanes the stagnation pressure and temperature are equal to ambient. The values are $100.8 \mathrm{kPa} \pm 1.25 \%$ and $289.5 \mathrm{~K} \pm 0.75 \%$ considering all cases. Measurements of the pressure around the annulus and downstream of the stator vanes are made using 8 pressure taps evenly distributed around the casing. The variation in circumferential pressure is approximately $\pm 1 \%$ of mainstream dynamic head. This pressure asymmetry is sinusoidal and consistent with the casing eccentricity relative to the disk (less than $\pm 1 \%$ of duct height). Eccentricity is discussed further in subsequent sections of this paper.

As the rotor blades do no turning, the high swirl flow in the exit duct must be de-swirled back to the axial direction before the exit plenum. Without de-swirl, the hub boundary layer is prone to large unstable separations due to an adverse pressure gradient. Oil paint flow visualisation shows that the hub boundary layer is fully attached.

Next, the seal geometries studied in this work are presented. 


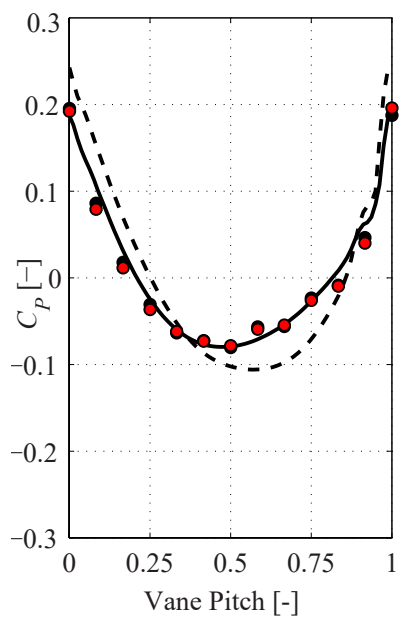

(a)

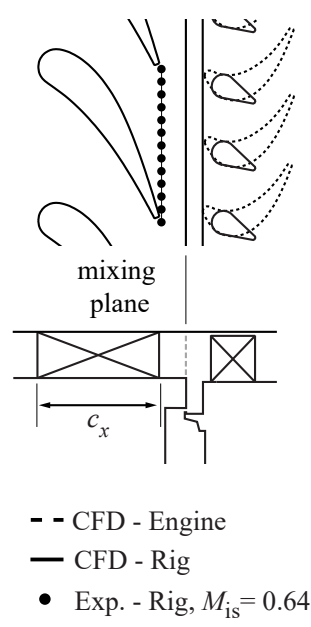

- Exp. - Rig, $M_{\text {is }}=0.20$

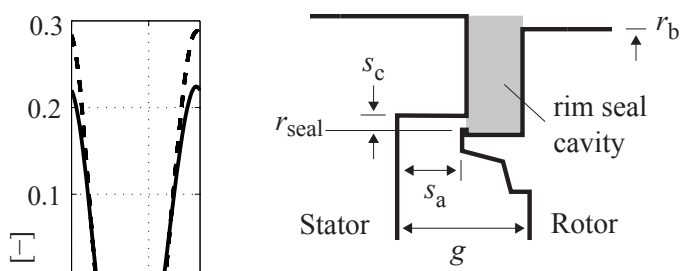

Single Lip Sea

$r_{\mathrm{b}}$ - rotor radius

$s_{\mathrm{o}}$ - seal lip axial overlap

$s_{\mathrm{a}}$ - distance from seal lip to stator

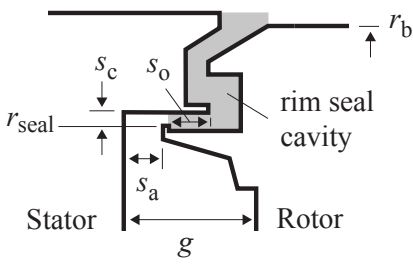

Double Lip Seal

$r_{\text {seal }}$ - seal lip radius

$s_{\mathrm{c}}$ - seal lip clearance

$g$ - rotor-stator cavity gap width

FIGURE 3. Sectional views of single lip and double lip seals. Not to scale.

rotational Reynolds number, $R e_{\theta}$, is $4.9 \times 10^{6}$ and $1.9 \times 10^{6}$, and the axial Reynolds number, $R e_{x}$, is $2.3 \times 10^{6}$ and $0.95 \times 10^{6}$ respectively. For brevity, the two flow conditions will be referred to as the high Re condition and the low Re condition. The testing was performed with and without blades in order to investigate the effect of a simulated engine blade pressure field on ingestion. Figure 4 summarises the range of operating conditions. In the case of the double lip seal, measurements of rotational ingress (no mainstream) were also performed.

The effect of relative flow angle at the rim seal on sealing effectiveness was also investigated (see fig. 4) for both rim seal geometries. This was achieved by sweeping through disk speeds at both vane exit Mach numbers. The sweep covers disk speeds either side of the engine matched flow coefficient (and hence velocity triangles). In these cases, the purge flow rate to the rotor-stator cavity was held fixed, corresponding to a rotorstator cavity seal effectiveness of $\sim 0.9$ at the engine matched flow coefficient.

\section{Purge Flow and Effectiveness Measurements}

Purge flow is delivered via a central bore in the stator hub, driven by the sub-atmospheric pressure in the rotor-stator cavity, and modulated by a valve. Carbon dioxide $\left(\mathrm{CO}_{2}\right)$ is mixed into the purge at approximately $4 \%$ by volume upstream of a flow conditioner. The mass flow rate of the seeded purge flow is measured with an ISO 5167-2:2003 compliant orifice plate.

Gas concentration measurements are used to evaluate concentration seal effectiveness, $\varepsilon_{\mathfrak{c}}$, defined as

$$
\varepsilon_{\mathrm{c}}=\frac{\chi_{\mathrm{n}}-\chi_{\infty}}{\chi_{\text {purge }}-\chi_{\infty}}
$$

where $\chi_{\text {purge }}$ is the concentration of the seeded purge flow, $\chi_{\infty}$ is the concentration of the unseeded mainstream and $\chi_{\mathrm{n}}$ is the concentration at a measurement point.

The gas concentration is measured using a 17 channel NDIR system. The gas is sampled using positive displacement pumps, so the measurements are taken at stable atmospheric conditions. The sensors are checked against pre-mixed BOC Alpha Standard gases at $2 \%$ and $4 \% \mathrm{CO}_{2}$ by volume in $\mathrm{N}_{2}$, with $\mathrm{CO}_{2}$ concentration uncertainty of $\pm 1 \%$. All sensors have a 13 point characterisation against the purge flow inlet sensor. The 
Purge flow sweep at engine matched flow coefficient

\begin{tabular}{|c|c|c|c|c|c|}
\hline & $\omega[\mathrm{rpm}]$ & vane exit $M_{\text {is }}[-]$ & $\operatorname{Re}_{\theta}[-]$ & $R e_{x}[-]$ & $C_{w}[-]$ \\
\hline \multirow[t]{2}{*}{$D<$} & 2450 & 0.64 & $4.9 \times 10^{6}$ & $2.30 \times 10^{6}$ & $740-1720$ \\
\hline & 800 & 0.20 & $1.9 \times 10^{6}$ & $0.95 \times 10^{6}$ & $400-7400$ \\
\hline \multirow[t]{2}{*}{$\Delta<$} & 2450 & 0.64 & $4.9 \times 10^{6}$ & $2.30 \times 10^{6}$ & 710 \\
\hline & 800 & 0.20 & $1.9 \times 10^{6}$ & $0.95 \times 10^{6}$ & $200-7300$ \\
\hline \multirow[t]{2}{*}{$\Delta<$} & 2450 & 0.64 & $4.9 \times 10^{6}$ & $2.30 \times 10^{6}$ & 320 \\
\hline & 800 & 0.20 & $1.9 \times 10^{6}$ & $0.95 \times 10^{6}$ & $290-7500$ \\
\hline \multirow[t]{2}{*}{$\triangle<$} & 2450 & 0.64 & $4.9 \times 10^{6}$ & $2.30 \times 10^{6}$ & $360-11900$ \\
\hline & 800 & 0.20 & $1.9 \times 10^{6}$ & $0.95 \times 10^{6}$ & $280-7300$ \\
\hline
\end{tabular}

Purge flow sweep without mainstream flow (rotational ingress)

\begin{tabular}{rrrrrr}
\hline$\omega[\mathrm{rpm}]$ & vane exit $M_{\mathrm{is}}[-]$ & $R e_{\theta}[-]$ & $R e_{x}[-]$ & $C_{w}[-]$ \\
\hline 2450 & no mainstream & $5.9 \times 10^{6}$ & 0 & $400-5150$ \\
800 & no mainstream & $1.9 \times 10^{6}$ & 0 & $370-1750$
\end{tabular}

Disk speed sweep at fixed purge flow rate and vane exit Mach number

\begin{tabular}{|c|c|c|c|c|c|}
\hline & $\omega[\mathrm{rpm}]$ & vane exit $M_{\text {is }}[-]$ & -] $R e_{\theta}[-]$ & $\operatorname{Re}_{x}[-]$ & $C_{w}[-]$ \\
\hline 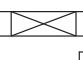 & & & $0.2-7.5 \times 10^{6}$ & $2.30 \times 10^{6}$ & -5150 \\
\hline & $25-1300$ & 0.20 & $0.06-$ & $0.95 \times 10^{6}$ & $\sim 2000$ \\
\hline & $\begin{array}{l}0-3520 \\
0-1300\end{array}$ & 0.20 & $\begin{array}{l}0-7.3 \times 10^{6} \\
0-3.2 \times 10^{6}\end{array}$ & $\begin{array}{l}2.30 \times 10^{6} \\
0.95 \times 10^{6}\end{array}$ & $\begin{array}{l}\sim 2800 \\
\sim 1000\end{array}$ \\
\hline
\end{tabular}

FIGURE 4. Table of experimental studies performed on the single lip and double lip seals.

short term drift is tracked during runs using online calibration valves. The worst case uncertainty in seal effectiveness is estimated from the calibration data to be within $\pm 1 \%$ (Savov [39]). At all data points presented in this paper, the gas concentration is sampled for $30 \mathrm{~s} \mathrm{(at} 2 \mathrm{~Hz}$ ) and averaged. The typical peak-topeak fluctuation of the readings over the sample period is similar to the sensor uncertainty at $\pm 1 \%$.

Traditionally, seal effectiveness characteristics have been plotted with the purge flow rate represented as $C_{w}$ (purge flow rate normalised by disk radius and cavity viscosity). Such plots do not scale across different Reynolds numbers. Presentation of the data in this paper follows Sangan et al. [16] [40] and Scobie et al. [41] who use the sealing parameter, $\Phi$, defined as

$$
\Phi=\frac{\dot{m}_{\text {purge }}}{2 \rho_{\text {seal }} \pi r_{\text {seal }}^{2} \omega s_{\mathrm{c}}}=\frac{V_{\text {seal }, x}}{r_{\text {seal }} \omega}
$$

where $\dot{m}_{\text {purge }}$ is the purge flow rate, $r_{\text {seal }}$ is the seal radius, $\rho_{\text {seal }}$ is the density, $s_{\mathrm{c}}$ is the seal clearance, $\omega$ is the rotational speed of the rotor disk and $V_{\text {seal }, x}$ is the axial mass-averaged velocity of net egress across the rim seal lip.

Sangan et al. and Scobie et al. showed that, using $\Phi$, collapsed their data at three rotational Reynolds numbers. It can be seen from the definition in eq. 2, and the schematic in fig. 5, that $\Phi$ actually represents a velocity ratio or equivalent flow coefficient for net flow through the rim seal. It is related to the relative flow angle of net egress across the seal lip.

\section{STEADY RESULTS AND DISCUSSION}

The sections below present and discuss measurement data across the different test conditions.

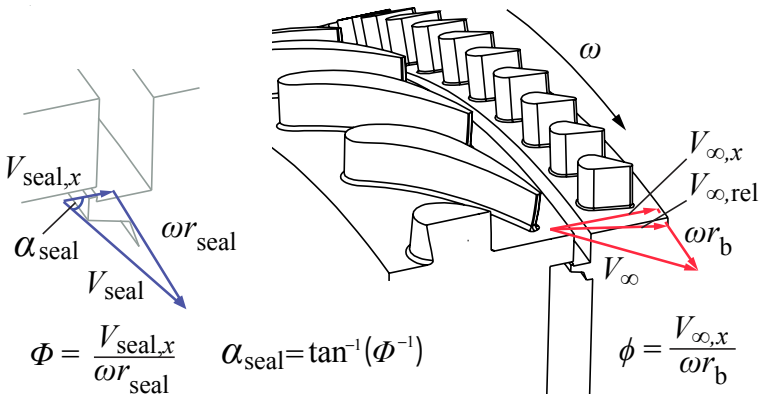

FIGURE 5. Schematic illustration of sealing parameter, $\Phi$, and mainstream flow coefficient, $\phi$.

Effectiveness versus Purge Flow Rate Figure. 6 plots concentration seal effectiveness, $\varepsilon_{\mathrm{c}}$, in the rotor-stator cavity across the range of purge mass flow rates for all purge flow sweeps performed on the single lip and double lip seals. The seal effectiveness is plotted at a radial height, $r / r_{\mathrm{b}}$, of 0.93 near the top of the rotor-stator cavity and just radially inwards of the rim seal.

Figure 6 shows that the sealing effectiveness curves scale well with purge flow rate when plotted as sealing parameter for a given rim seal geometry.

It can be seen that the single lip geometry has sensitivity between the high Re and low Re conditions both with and without blades for $\varepsilon_{\mathrm{c}}<0.95$. Higher $\varepsilon_{\mathrm{c}}$ is achieved at lower $\Phi$ for the high Re condition. As will be discussed later, the sensitivity is possibly due to the more stable shear layer interaction between the mainstream and rim seal flows at lower Reynolds numbers, where the relative effects of viscosity are greater.

For all cases in fig. 6 with a mainstream flow, the seal effectiveness curves asymptote to but do not reach a value of 1 . In all cases, the high Re condition data shows a lower seal effectiveness than that at the low Re condition for the same $\Phi$ (peak values of $\varepsilon_{\mathrm{c}} \sim 0.98$ at the high Re condition and $\varepsilon_{\mathrm{c}} \sim 0.99$ at the low Re condition). It is possible that the lower viscous damping at the higher Reynolds numbers allows more vigorous mixing in the rim seal cavity. It should be noted that the difference in peak seal effectiveness is within the measurement uncertainty.

Plots of seal effectiveness versus purge flow rate which asymptote to a value of less than 1 can also be observed in other studies with a mainstream such as by Gentilhomme et al. [15], Bohn et al. [20], Okita et al. [42] and Chew et al. [18]. Bohn et al. [10], who studied the effect of the introduction of vanes on rim seal ingestion, noted that the maximum seal effectiveness did not reach 1 when vanes were introduced in the mainstream. Chew et al. [18], who also studied the effect of the introduction of vanes, conjectured that this could be due to interaction between the mainstream and purge at the rim seal. This hypothesis is backed up by measurements on the double lip seal in the absence of a mainstream (fig. 6). In this case the seal effectiveness reaches unity for the two Reynolds number cases shown. The data of Sangan et al. [43] shows a similar behaviour. As will be shown later in this paper, the level of shear layer interaction between the mainstream and the rim seal flow can affect the level of ingress into the rotor-stator cavity.

Comparing the performance of the two seal geometries in 


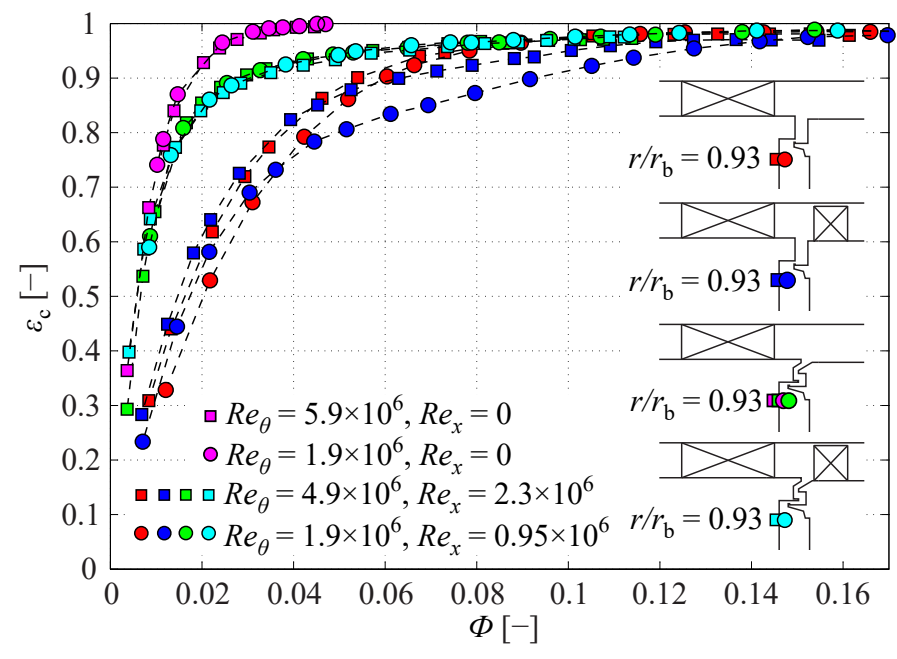

FIGURE 6. $\quad \varepsilon_{\mathrm{c}}$ vs $\Phi$ curves for the single lip and double lip seals at high and low Re conditions with and without blades, at an enginematched mainstream flow coefficient. Double lip seal measurements without mainstream flow are also plotted.

fig. 6, a clear distinction exists between the effectiveness curves of the double lip and single lip seals. For the same amount of coolant flow, the double lip geometry seals significantly better than the single lip. However, being a better seal, the sealing effectiveness performance curve of the double lip geometry has a steeper gradient of seal effectiveness at lower purge flow rates than the single lip seal. The double lip seal has a larger sensitivity in seal effectiveness for the same absolute uncertainties in purge flow. This is true in particular for seal effectiveness values in the range of 0.7-0.9, within which typical engine design targets would lie. From a practical point of view, maintaining a similar margin of safety with a better seal would need a higher seal effectiveness design target or lower purge flow uncertainty.
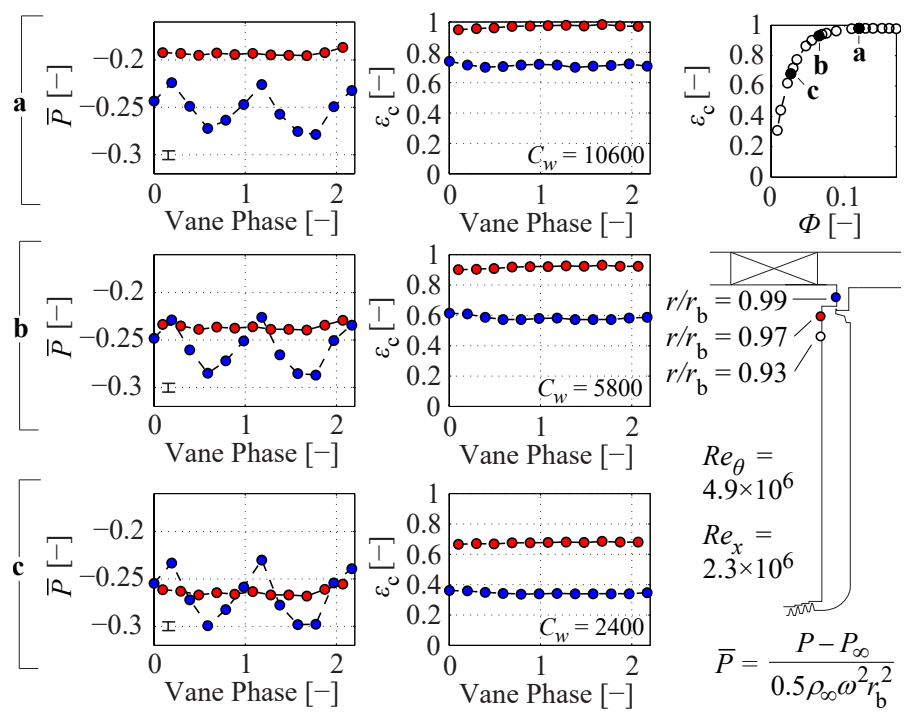

I typical uncertainty in $\bar{P}( \pm 0.0046)$

FIGURE 7. Unbladed single lip seal: Normalized pressure, $\bar{P}$, and seal effectiveness, $\varepsilon_{\mathrm{c}}$, across two vane pitches in the rim seal and rotorstator cavities across three values of $\Phi$.
Sensitivity to Blade Pressure Field From fig. 6, it can also be seen that while the double lip seal is insensitive to the addition of a simulated engine blade pressure field, the presence of a blades reduces the performance of the single lip seal, particularly in the region of $\varepsilon_{\mathrm{c}} 0.8-0.95$. At the low Re condition, the bladed single lip seal requires an approximately $50 \%$ higher value of $\Phi$ to reach $\varepsilon_{\mathrm{c}}=0.9$ than the unbladed case. As will be shown below, the larger gradient in seal effectiveness across the seal lip in the case with blades which is indicative of increased mixing in the rim seal cavity.

Variations with Vane Phase Figures 7 and 8 show plots of the normalized pressure field, $\bar{P}$, (left hand side plots in each figure) and seal effectiveness, $\varepsilon_{\mathrm{c}}$, (right hand side plots in each figure) against vane phase. The data is measured at $r / r_{\mathrm{b}}=0.97$ (inside the rotor-stator cavity) and at $r / r_{\mathrm{b}}=0.99$ (inside the rim seal cavity). Figure 7 shows data for the single lip seal and fig. 8 shows data for the double lip seal. Both figures show data at the high Re condition without blades. The pressure field and seal effectiveness are measured over 2.2 vane passages at three purge flow rates, labelled $\mathbf{a}, \mathbf{b}$ and $\mathbf{c}$. The typical uncertainty in $\bar{P}$ is calculated using root square sum addition [44] at \pm 0.0046 and shown for scale in figs. 7 and 8 .

The rotor-stator cavity pressure is set by the mainstream pressure (a function of mainstream Mach number) and the pressure drop across the rim seal which is a function of the flow rate through it. Considering the left hand sides of figs. 7 and 8, it can be seen that the vane pressure profile is clearly defined in the rim seal cavity (blue circles). The magnitude of the vane pressure field variation is attenuated across the radial lip of the rim seal, and at the top of the rotor-stator cavity, the pressure measurements have a near constant value (red circles).

Moving from plot (a) to (c) in figs. 7 and 8, the rotor-stator cavity pressure begins to drop with reducing purge flow rate. As it drops, the rotor-stator cavity pressure starts to overlap the

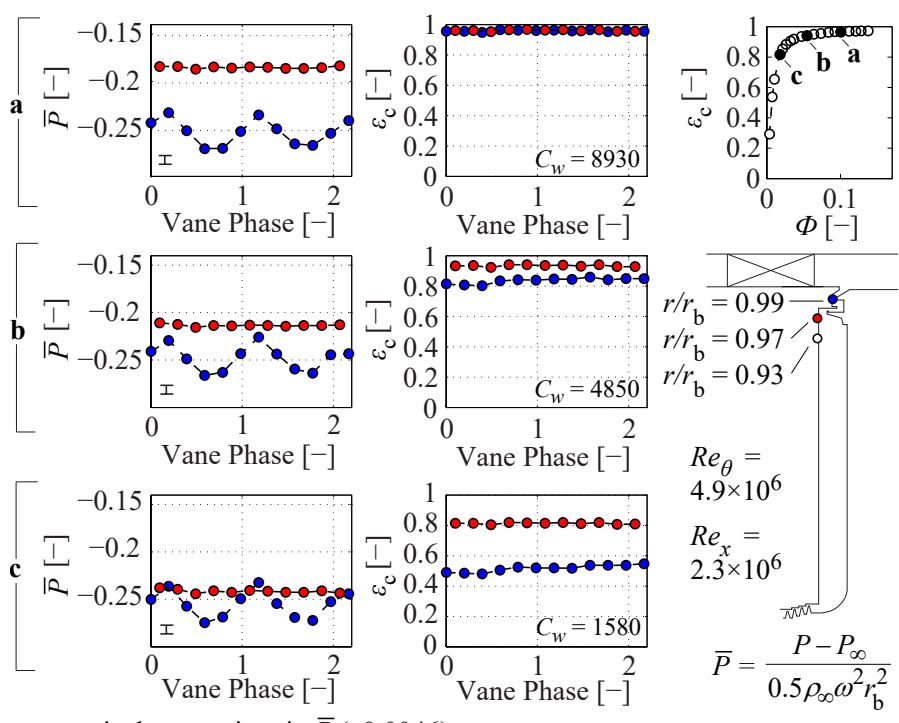

I typical uncertainty in $\bar{P}( \pm 0.0046)$

FIGURE 8. Unbladed double lip seal: Normalized pressure, $\bar{P}$, and seal effectiveness, $\varepsilon_{\mathrm{c}}$, across two vane pitches in the rim seal and rotorstator cavities across three values of $\Phi$. 


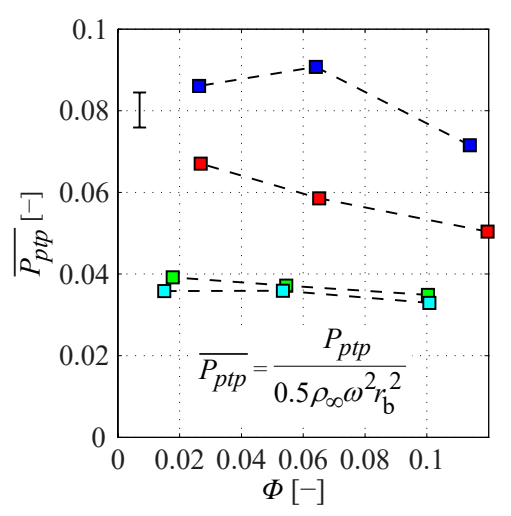

I typical uncertainty in $\overline{P_{p t p}}( \pm 0.0043)$

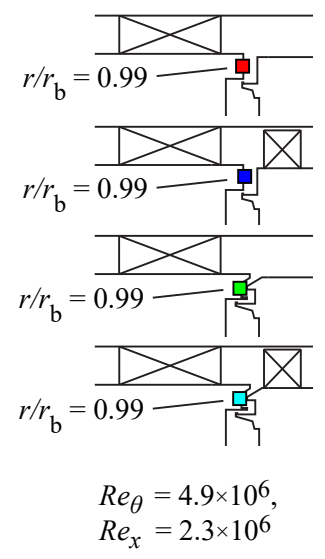

FIGURE 9. Vane pressure field peak to peak pressures for the single lip and double lip seals bladed and unbladed at the High Re condition.

pressure profile in the rim seal cavity and ingress into the cavity increases. It should be noted that figs. 7 and 8 do not show clear trends in seal effectiveness associated with the shape of the vane pressure field indicating that the flow is well-mixed at the measurement points.

Fig. 9 shows a plot of the normalised peak-to-peak pressure, $\overline{P_{\mathrm{ptp}}}$, in the rim seal cavity (at $r / r_{\mathrm{b}}=0.99$ ) across 2.2 vane pitches. This peak-to-peak pressure is plotted for the bladed and unbladed single lip and double lip seals at the high Re condition. $\overline{P_{\mathrm{ptp}}}$ is computed as the difference between the average of the two peaks and the average of the two troughs in the rim seal pressure profiles normalised by a dynamic head equivalent to disk preripheral velocity. The typical root square sum uncertainty [44] in $\overline{P_{\text {ptp }}}$ is \pm 0.0043 .

From fig. 9, at similar $\Phi$, the vane pressure field in the rim seal cavity is over $50 \%$ stronger for the single lip seal than for the double lip seal. The radial location of the measurement points is the same for both seals. The double lip seal has an additional (upper) lip that overhangs the measurement location. This increases the path between the measurement points in the rim seal cavity and the vane trailing edge, allowing a longer distance for the vane pressure field to decay and mixing to occur.

As the pressure drop across a seal is proportional to the flow rate, a weaker vane pressure field at the seal lip (i.e. smaller peak-to-peak pressure) would mean that a smaller change in flow rate would be sufficient to create a pressure difference across the seal lip, $\Delta P_{\text {seal }}$, equivalent to $P_{\mathrm{ptp}}$. For time-mean ingress into the cavity (as driven by the vane pressure field), this means that over a smaller change in $\Phi$, the cavity would go from no ingestion to full ingestion (or vice-versa). This would explain the steeper slope of the double lip $\varepsilon_{\mathrm{c}}$ versus $\Phi$ curves (fig. 6).

From fig. 9, it can also be seen that the addition of rotor blades increases the magnitude of the peak-to-peak pressure measured in the single lip seal (by over 20\%). As will be shown in later sections of this paper, the addition of blades also acts to suppress the shear layer instabilities between the mainstream and rim seal cavity flows. A weaker shear layer interaction (as in the presence of blades) would result in less attenuation of the vane pressure field across the shear layer.

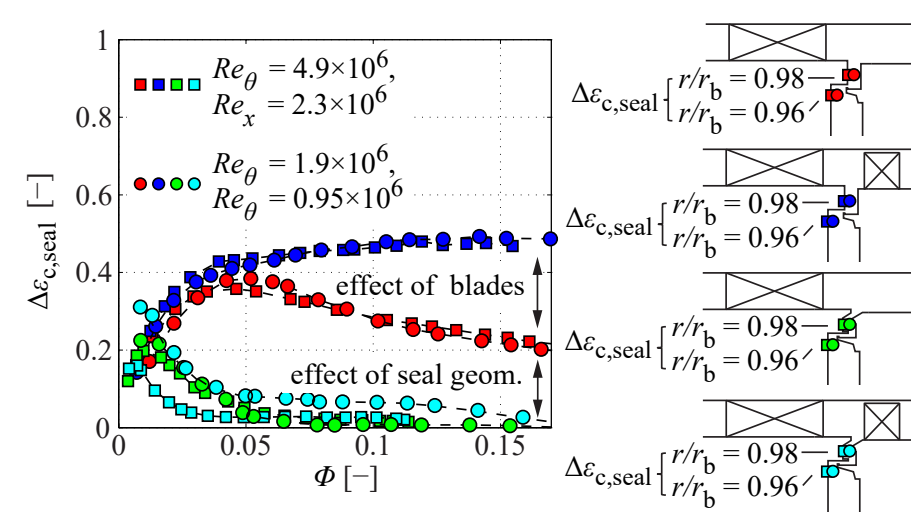

FIGURE 10. Difference in $\varepsilon_{\mathrm{c}}$ across the single lip and double lip seals plotted against $\Phi$ and against cavity $\varepsilon_{\mathrm{c}}$

Rim Seal Effectiveness Gradient Comparing points (a) and (b) of figs. 7 and 8 indicates that the single lip seal has a significantly larger difference in seal effectiveness across the seal lip. Fig. 10 plots the difference in seal effectiveness across the rim seal lip, $\Delta \varepsilon_{\mathrm{c}, \text { seal }}$, against sealing parameter, $\Phi$, where $\Delta \varepsilon_{\mathrm{c}, \text { seal }}$ is defined as the difference in seal effectiveness between a point at $r / r_{\mathrm{b}}=0.96$ and a point at $r / r_{\mathrm{b}}=0.98$.

Two trends are visible from fig. 10. These are the difference in $\Delta \varepsilon_{\mathrm{c}, \text { seal }}$ between the double lip and single lip seals and the difference in $\Delta \varepsilon_{\mathrm{c}, \text { seal }}$ between the bladed and unbladed single lip seals.

The highest $\Delta \varepsilon_{\mathrm{c}, \text { seal }}$ occurs for the bladed single lip seal. At values of seal effectiveness lower than approximately 0.8 , the unbladed single lip seal exhibits the same trends as the bladed configuration in fig. 10. However, for higher values of seal effectiveness, $\Delta \varepsilon_{\mathrm{c}, \text { seal }}$ decreases with increasing $\Phi$ creating an increasing gap in $\Delta \varepsilon_{\mathrm{c} \text {,seal }}$ between the bladed and unbladed single lip seals. Unlike for the bladed single lip seal, $\Delta \varepsilon_{\mathrm{c}, \text { seal }}$ falls with increasing purge flow rate for the unbladed single lip seal.

The values of cavity seal effectiveness at which the difference in $\Delta \varepsilon_{\mathrm{c}, \text { seal }}$ between the bladed and unbladed single lip seals begins to grow $\left(\varepsilon_{\mathrm{c}}>0.8\right)$ are also the values of cavity seal effectiveness at which the characteristic $\varepsilon_{\mathrm{c}}$ versus $\Phi$ curves begin to deviate (see fig. 6). Assuming similar levels of fluid transport across the rim seal, a configuration with a higher $\Delta \varepsilon_{\mathrm{c}, \text { seal }}$, such as the bladed single lip seal, would result in increased ingestion into the cavity.

The larger $\Delta \varepsilon_{\mathrm{c}, \text { seal }}$ of the bladed single lip seal compared to its unbladed configuration is attributed to enhanced mixing in the rim seal cavity (likely as a result of increased blockage introduced by the blades) acting to lower the seal effectiveness in this region. Apart from the larger gradient in seal effectiveness across the seal lip, evidence of increased mixing in the rim seal cavity can be obtained by comparing radial $\varepsilon_{\mathrm{c}}$ values between the bladed and unbladed single lip seal configurations. At both the high and low Re conditions, the bladed single lip configuration has a steeper gradient of decreasing $\varepsilon_{\mathrm{c}}$ radially outwards in the rim seal cavity than its unbladed counterpart. A comparison of these radial profiles at the high Re condition at a similar purge flow rate is shown in fig. 11.

From fig. 10, it can be seen that for similar flow rates and 

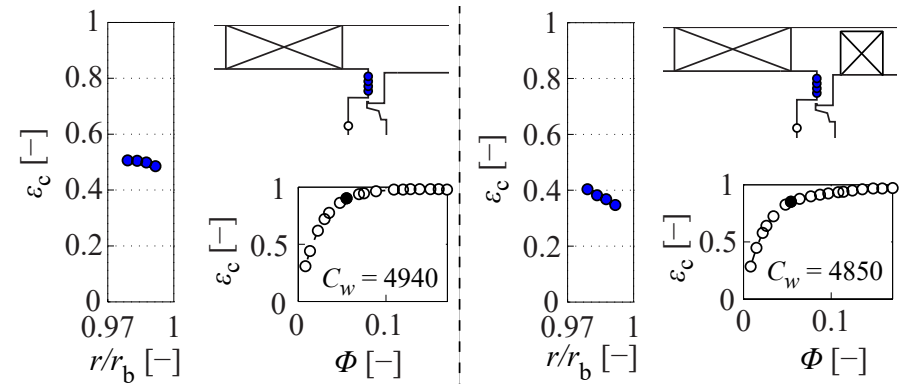

FIGURE 11. Radial seal effectiveness profile in the rim seal cavity for the single lip seal.

levels of cavity seal effectiveness, $\Delta \varepsilon_{\mathrm{c}, \text { seal }}$ is lower in the case of the double lip seal than in the case of the single lip seal. One would expect that for a similar level of transport across the seal lip, there would be less ingestion into the rotor-stator cavity across the double lip seal than across the single lip seal.

\section{Circumferentially Non-Uniform Ingress Circum-} ferential seal effectiveness profiles at three purge flow rates (labelled $\mathbf{a}, \mathbf{b}$ and $\mathbf{c})$ are plotted in fig. 12 for the unbladed single lip seal at the high Re condition.

At low purge flow (plot c), a peak-to-peak variation in seal effectiveness of approximately 0.15 , or $25 \%$ of the mean value, is measured near the rim seal at $r / r_{\mathrm{b}}=0.93$. At higher purge flows - plots $\mathbf{b}$ then $\mathbf{a}$ - the circumferential variation decreases. When the cavity is near fully sealed (plot a), the circumferential variation falls to below $1 \%$ of the mean value of $\varepsilon_{\mathrm{c}}$. This circumferential trend at $r / r_{\mathrm{b}}=0.93$ (cavity top) is in phase with the eccentricity at the rim seal.

The eccentricity of the rim seal, $e / s_{c}$, was set to a small but finite value of $\pm 12 \%$. It is measured in-situ with a plunger dial gauge fixed to the disk (shown in the lower plot). The central bore is concentric to the casings and used as a reference. Where the eccentricity is negative, corresponding to a larger than average seal clearance, the seal effectiveness is lower than the mean value. The spread in measured rim seal eccentricity is due to small offsets between the individual seal pieces, and the gaps in the data occur when the dial gauge is not visible through the stator. ${ }^{1}$ The clearance of the labyrinth seal at inlet to the rotorstator cavity is $90 \%$ larger than at the rim seal, corresponding to $50 \%$ lower eccentricity.

In this case the lower effectiveness data coincides with the largest seal clearance. However, further work is necessary to confirm the actual cause of the non-uniform ingestion and interactions with the mainstream cannot yet be excluded.

Relative to the data near the rim seal, the variation in seal effectiveness at $r / r_{\mathrm{b}}=0.79$, is both reduced in magnitude and shifted in phase. This trend suggests that low effectiveness fluid from the top of the cavity undergoes limited mixing as it spirals radially inwards within the stator boundary layer. Such a flow path is illustrated in fig. 13, a. The stiff rotating core confines radial transport to thin boundary layers on the rotor and stator disks.

\footnotetext{
${ }^{1}$ Steps between rim seal pieces are analogous to the engine rim seal which is formed by discrete blades and vanes.
}
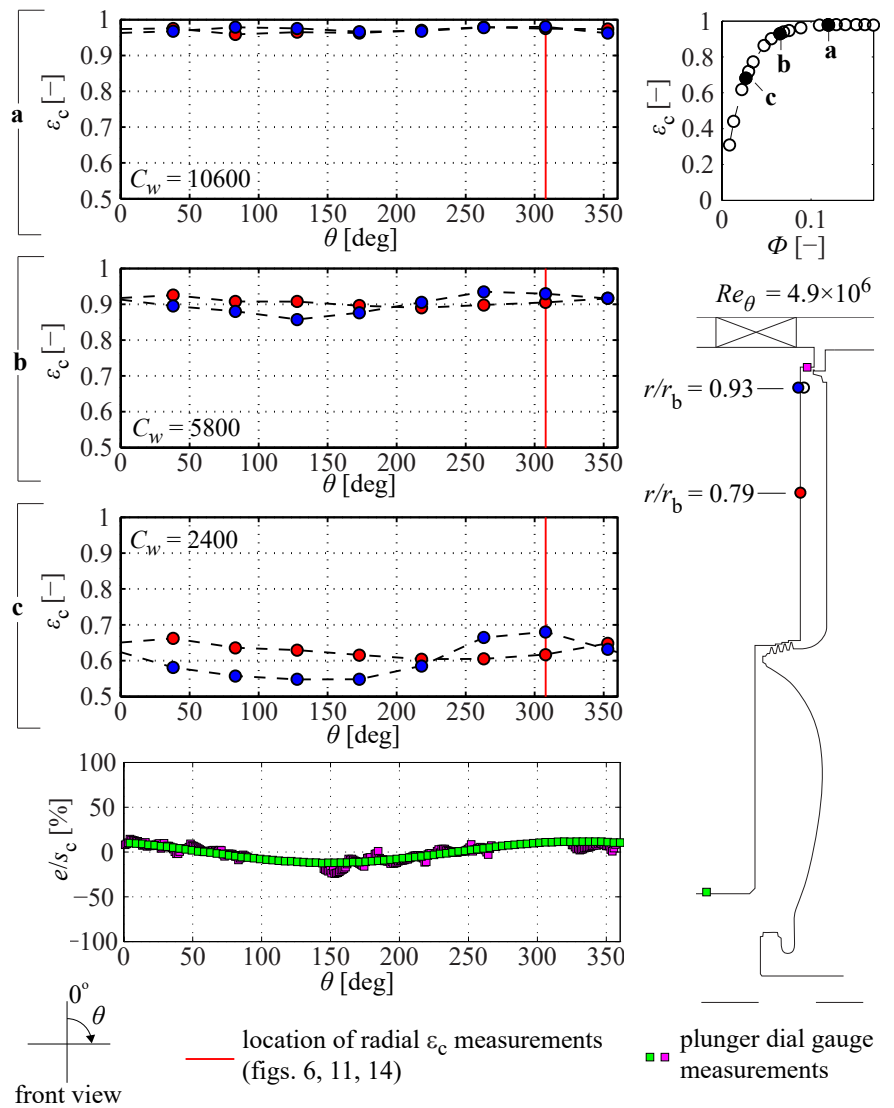

FIGURE 12. Unbladed configuration of single lip seal at the high Re condition: circumferential $\varepsilon_{\mathrm{c}}$ for three values of $\Phi$ labelled $\mathbf{a}, \mathbf{b}$ and $\mathbf{c}$ and eccentricity, $e$, measurements relative to seal clearance, $s_{c}$.

Further evidence of this flow structure is found in the radial profile of seal effectiveness. Figure 13, b shows measurements taken at the radial plane marked by the red line in fig. 12. At this location the effectiveness at $r / r_{\mathrm{b}}=0.93$ is higher than at $r / r_{\mathrm{b}}=$ 0.79 - indicated schematically by the blue and red hypothesized streamlines.

Data by Sangan et al. [45] for a radial overlap seal (replotted in fig. 13, c) also shows a radial increase in seal effectiveness. This could indicate the presence of circumferentially nonuniform ingestion.

Figure 14 plots the circumferential variation in seal effectiveness for the unbladed double lip seal. The magnitude and phase of the eccentricity profile is the same as for the single lip seal. From the circumferential $\varepsilon_{\mathrm{c}}$ plots, it can be seen that inside the rotor stator cavity the double lip seal features a markedly smaller circumferential variation in seal effectiveness than the single lip seal. As shown in fig. 10, the double lip seal has a smaller gradient in seal effectiveness, $\Delta \varepsilon_{\mathrm{c}}$ across the lower lip than the single lip configuration. This would act to attenuate the effect of flow field non-uniformity through the lower lip.

The circumferentially non-uniform data demonstrates the need for circumferential measurements, and it may be a contributory factor to the limited agreement between CFD and experimental data in open literature to date. 
(a) Hypothesized flow path along stator boundary layer:

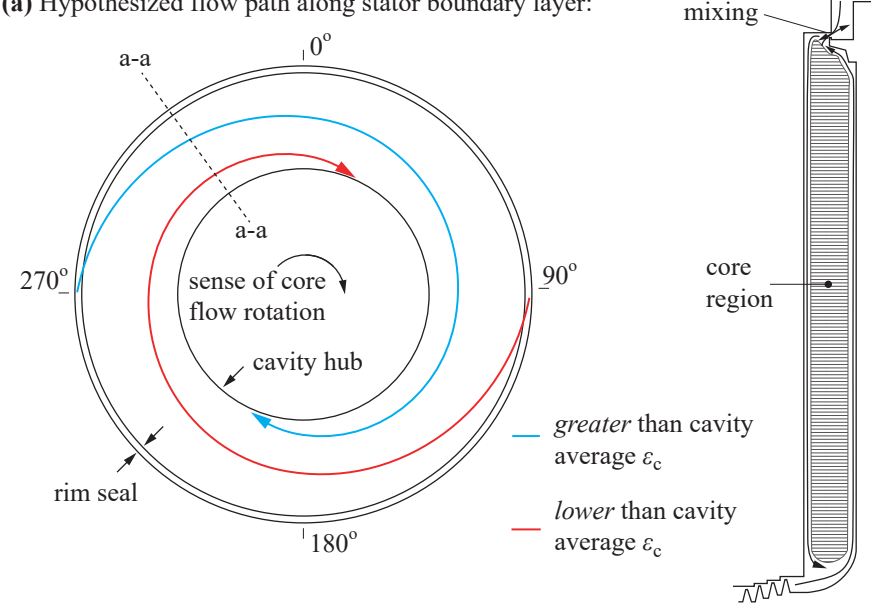

(b) Radial $\varepsilon_{\mathrm{c}}$ measurements (section a-a):

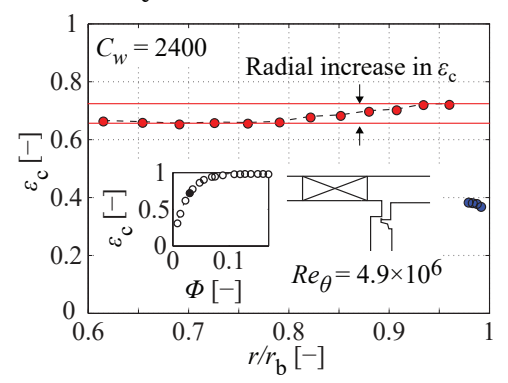

(c) In literature

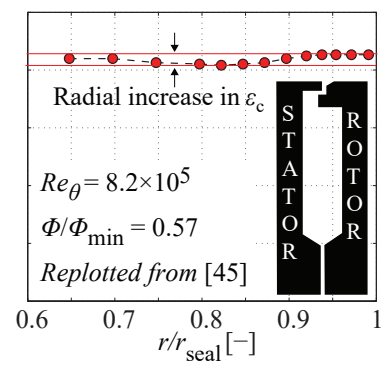

FIGURE 13. (a) Schematic representation of likely non-uniform ingestion pattern into the rotor-stator cavity. (b) Radial $\varepsilon_{\mathrm{c}}$ profiles at location a-a for unbladed single lip seal showing a radial increase in $\varepsilon_{\mathrm{c}}$. (c) A radial increase in seal effectiveness from literature Replotted from Sangan et al. [45]

\section{UNSTEADY MEASUREMENTS \& DISCUSSION}

Motivated by previous studies in literature, this paper examines the unsteady pressure in the rim seal and cavity for frequencies up to blade passing. Endevco 8507C-1 $6.9 \mathrm{kPa}$ differential pressure transducers are used to record unsteady pressure data on the stator side of the rotor-stator and rim seal cavities relative to atmosphere. Four sensors are used - one in the rim seal cavity, one in the rotor-stator cavity, one in the purge feed cavity and one (reference) left open to atmosphere. The sensors are sampled at $200 \mathrm{kHz}$ and data is recorded for at least $10 \mathrm{sec}-$ onds. The typical noise (observed on the reference sensor) was $\pm 2 \mathrm{~Pa}$. Blade passing (BPF) occurs at 96 times shaft rotational frequency $N$ (i.e. $96 N$ ). At $3.92 \mathrm{kHz}$, this is more than a factor 10 below the sensor's resonant frequency of $55 \mathrm{kHz}$.

Unsteady pressure data at the high Re condition is presented and discussed below. Although not shown, the same conclusions hold at the low Re condition. The unsteady data below is represented by spectrograms plotted over 60 disk revolutions $(\sim 1.5 \mathrm{~s})$. The spectrograms are computed using a Fast Fourier Transform (FFT) of windowed segments of the signal which cover approximately 5 disk revolutions $(0.125 \mathrm{~s})$, with a step of 0.1 disk revolutions $(0.0025 \mathrm{~s})$ between successive segments.

The following sections discuss the characteristics of the unsteady pressure signals for a range of purge flow rates. The modulation of the pressure signals by the blade pressure field and variations in main stream flow coefficient are highlighted.

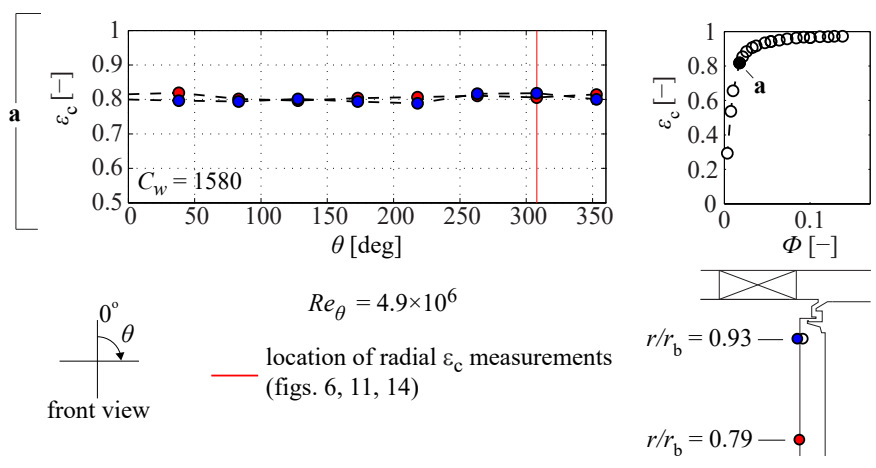

FIGURE 14. Unbladed configuration of double lip seal at the high Re condition: circumferential $\varepsilon_{\mathrm{c}} \sim 0.8$.

Effect of Blades and Purge Flow Rate Figures 15 and 16 show the effect of the addition of blades on the unsteady pressure measurements in the rim seal. Spectrograms are plotted for the bladed and unbladed single lip and double lip seals for frequencies of up to $100 \mathrm{~N}$ at three purge flow rates (labelled $\mathbf{a}, \mathbf{b}$ and $\mathbf{c})$. The spectrograms are normalised by the pressure difference across the seal, $\Delta P_{\text {seal }}$, for each configuration.

Comparing the top row of spectrograms (unbladed configuration) and the bottom row of spectrograms (bladed configuration) in figs. 15 and 16, a distinct peak is visible at $96 \mathrm{~N}$ (i.e. BPF) which effectively disappears with the removal of the blades. The faint trace at $96 \mathrm{~N}$, more clearly visible for the double lip seal, is due to shallow blade mounting pockets on the rotor disk.

The major difference between the top and bottom rows of spectrograms in figs. 15 and 16 is the presence of increased activity in the rim seal area for the unbladed cases, especially at lower flow rates. This is observed in the region of $25-35 \mathrm{~N}$ for the unbladed single lip seal and in the region of 30-40N for the unbladed double lip seal. For both seals, the activity is present at all flow rates (plots a to c). The band of frequencies widens with increased purge flow rate. This band of activity in the rim seal is likely to be associated with a Kelvin-Helmholtz (K-H) type shear layer instability driven by the high swirl angle of the mainstream flow at the rim seal cavity. K-H type instabilities have been previously documented in computational studies such as those by Rabs et al. [32] and Chilla et al. [31]. Rabs et al. noted the presence of a K-H type distortion of the free shear layers in simulations for a simple axial clearance seal where the swirl component of the mainstream is at $70^{\circ}$ to axial. As shown in the following section, at higher flow coefficients (with greater tangential velocity difference at the rim seal), the intensity of the spectral activity increases in line with increasing shear. The activity registered in the rim seal cavity generally does not appear in the rotor-stator cavity signals indicating that the fluctuations are attenuated by the rim seal. This suggests that they originate externally to the rotor-stator cavity.

Comparing the spectrograms for the unbladed single lip and double lip seals, there is a difference in the frequency range of the unsteady activity. It occurs at a higher frequency and over a narrower band for the double lip seal (in the range of 30-40N) than for the single lip seal (in the range of 25-35N). Chilla et al. [31] showed that, for the same boundary conditions, the 

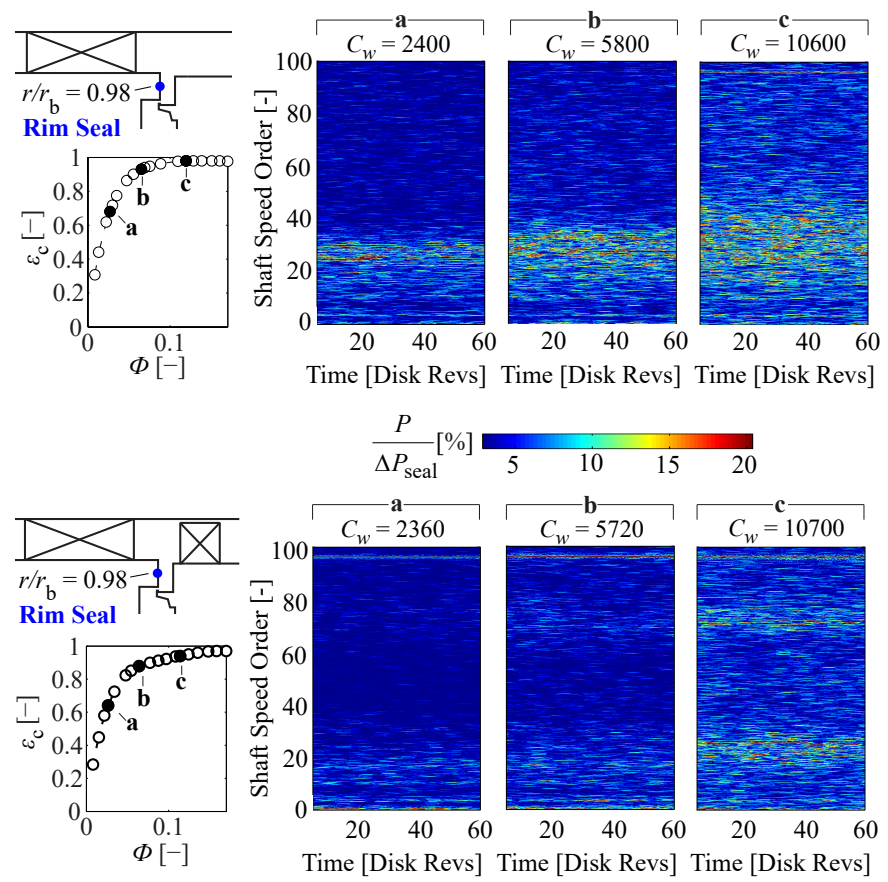

FIGURE 15. Spectrograms of the unsteady pressure in the rim seal cavity for the single lip seal with and without rotor blades at $R e_{\theta}=$ $4.9 \times 10^{6}$ and $R e_{x}=2.3 \times 10^{6}$. The spectrograms are plotted for 3 levels of cavity $\varepsilon_{\mathrm{c}}, \mathbf{a}, \mathbf{b}, \mathbf{c}$. Note: $\Delta P_{\text {seal }}$ is taken at a cavity $\varepsilon_{\mathrm{c}}$ of 0.875 .

shape and size of the rim seal cavity shifts the frequency of the unsteadiness. The double lip seal has a smaller cross sectional area and a narrower throat between the mainstream and rim seal cavity than the single lip (see fig. 3). If the unsteadiness is associated with a nominally constant Strouhal number $(S t=f l / V$, where $f$ is frequency, $l$ is a characteristic length and $V$ is a characteristic velocity), a higher frequency would be expected in the narrower and smaller double lip rim seal cavity.

The addition of rotor blades attenuates the activity in the rim seal. In the numerical study performed by Rabs et al. [32], the authors showed that the addition of blades suppressed the instabilities. However, the K-H type instabilities they observed could still occur in the bladed simulations, although only at high flow rates and with reduced magnitude and frequency. Evidence of similar behaviour is also observed in the present study where, as shown in figs. 15 and 16, bands of spectral activity begin to occur for the bladed seal configurations (around $25 \mathrm{~N}$ and $70 \mathrm{~N}$ for the single lip seal and $20 \mathrm{~N}$ and $75 \mathrm{~N}$ for the double lip seal) at high purge flow rates (spectrograms c). The lower of the frequency bands for each bladed configuration is at approximately $10 \mathrm{~N}$ lower frequency than the activity seen in the corresponding unbladed case, in agreement with the findings of Rabs et al.

The spectral activity for the bladed cases occupies two frequency ranges. The spectrograms show that the higher frequency range, which is not registered in the unbladed cases, occupies frequencies at BPF $(96 N)$ minus the lower range of spectral activity. Also, as can be seen from the spectrograms, the activity associated with the higher frequency range is weaker in magnitude. This would imply that the activity associated with the higher frequency range is simply the side-band resulting from the addition of the BPF to the lower frequency activity.
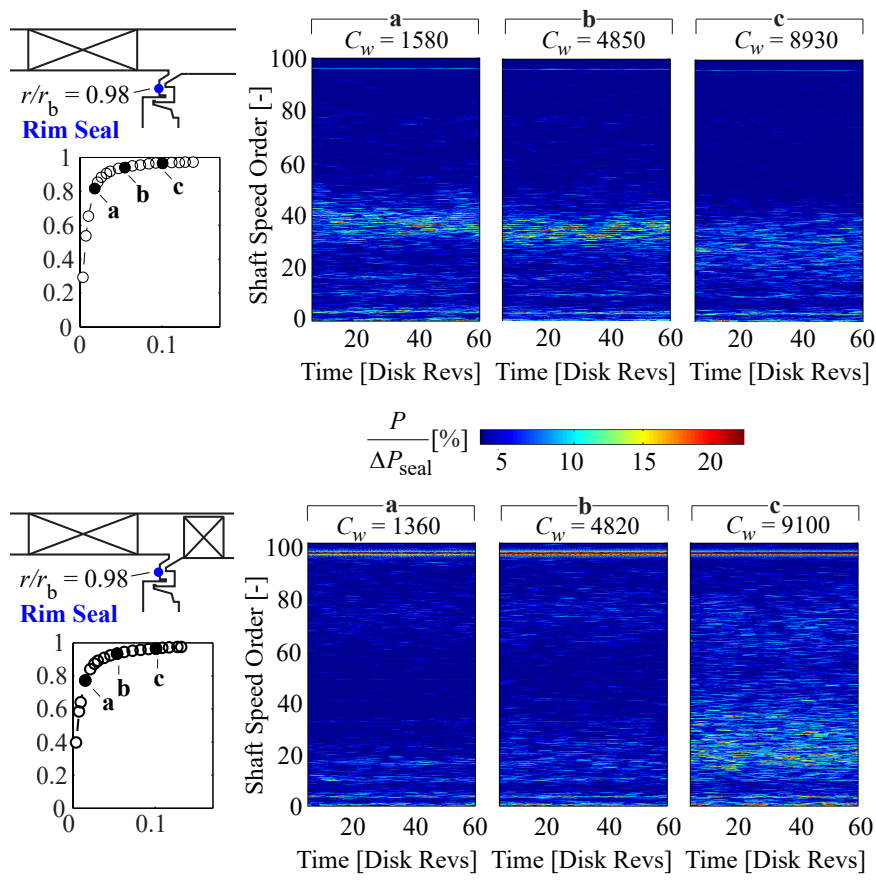

FIGURE 16. Spectrograms of the unsteady pressure in the rim seal cavity for the double lip seal with and without rotor blades at $R e_{\theta}=$ $4.9 \times 10^{6}$ and $R e_{x}=2.3 \times 10^{6}$. The spectrograms are plotted for 3 levels of cavity $\varepsilon_{\mathrm{c}}, \mathbf{a}, \mathbf{b}, \mathbf{c}$. Note: $\Delta P_{\text {seal }}$ is taken at a cavity $\varepsilon_{\mathrm{c}}$ of 0.925 .

Similar observations were made by O'Mahoney et al. [24] for a CFD study carried out on a rim seal with vanes and blades. The authors plotted FFT spectra for virtual probes in the rim seal which show peaks at $0.35 \mathrm{BPF}$ and at $0.65 \mathrm{BPF}$ where the magnitude of the peak at $0.65 \mathrm{BPF}$ is weaker than that at $0.35 \mathrm{BPF}$.

As will be shown in the following section, the unsteady fluctuations in the rim seal act to increase mixing at greater levels of mainstream shear (higher mainstream flow coefficient). However, from the characteristic seal effectiveness, $\varepsilon_{\mathrm{c}}$, versus sealing parameter, $\Phi$, curves in fig. 6 the bladed single lip seal is shown to perform worse than the unbladed one. Similarly, from fig. 10, the bladed single lip seal features a larger difference in seal effectiveness across the rim seal than the unbladed single lip seal. This would suggest that the blade pressure field has a more dominant role in increasing mixing in the rim seal than the unsteadiness it suppresses.

It should be further noted here that at lower absolute Reynolds numbers, the relative effects of viscosity are larger and any shear layer interaction would be more stable. Although not plotted here, evidence of this is seen in the FFTs of the unsteady pressure measurements in the rim seal - the band of unsteady activity has a more clearly defined peak and the addition of blades has a notably weaker suppressing effect on the unsteadiness at the low Re condition. This would help explain the sensitivities in $\varepsilon_{\mathrm{c}}$ vs $\Phi$ characteristics at the two $R e$ conditions for the single lip seal (fig. 6). As the double lip seal has a markedly smaller gradient in seal effectiveness across the seal lip (fig. 10), it would be expected that the rotor-stator cavity is less sensitive to the effects of Reynolds number on the shear layer interaction and, hence, the absence of visible sensitivities in the double lip seal $\varepsilon_{\mathrm{c}}$ vs $\Phi$ curves in fig. 6. 

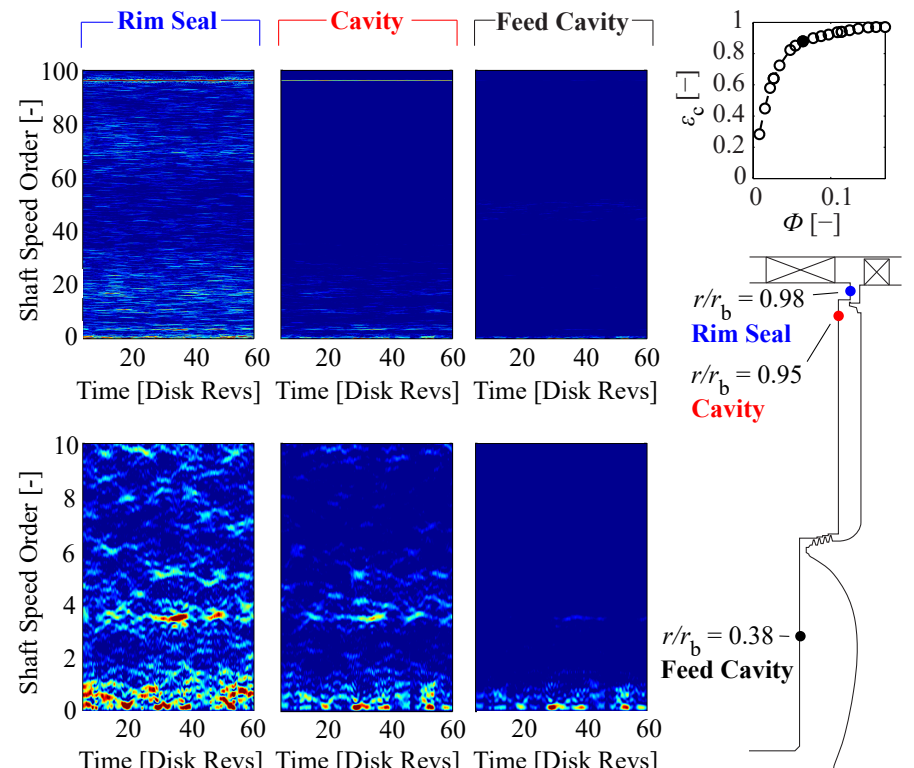

Time [Disk Revs] Time [Disk Revs] Time [Disk Revs]
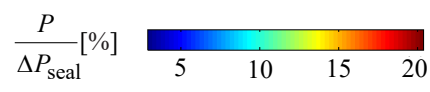

$R e_{\theta}=4.9 \times 10^{6}$

$C_{w}=572$

FIGURE 17. Single lip seal, bladed configuration at $R e_{\theta}=4.9 \times 10^{6}$, $R e_{x}=2.3 \times 10^{6}$ and cavity $\varepsilon_{\mathrm{c}} \sim 0.9$ : Spectrograms of the unsteady pressure signal at three radial locations (rim seal, rotor-stator cavity, and purge feed cavity) over 60 disk revolutions.

Very Low Order Unsteadiness Fig. 17 presents spectrograms of unsteady data at 3 locations along the same radial line for the bladed single lip seal. The upper spectrograms are plotted for frequencies of up to $100 \mathrm{~N}$ (approximately $4060 \mathrm{~Hz}$ ). The lower row of spectrograms are a zoom-in into the 0 to $10 \mathrm{~N}$ ( 0 to $40.6 \mathrm{~Hz}$ ) range. The measurement points are in the rim seal cavity $\left(r / r_{\mathrm{b}}=0.98\right)$, in the rotor-stator cavity near the rim seal $\left(r / r_{\mathrm{b}}=0.95\right)$, and in the purge feed cavity $\left(r / r_{\mathrm{b}}=0.38\right)$. The corresponding cavity seal effectiveness is approximately 0.9 .

From the $0-10 \mathrm{~N}$ spectrograms, distinct pressure oscillations can be observed at over an order of magnitude below blade passing - around $1 N$ and in the range of 3-5N for both the single lip and double lip seals. They appear over long time scales (multiple disk revolutions) and do not exhibit any clear periodicity in time. The magnitude of these fluctuations is highest in the rim seal cavity, followed by the rotor-stator cavity and feed cavity. This would suggest that this unsteadiness originates from the mainstream, externally to the rotor-stator cavity. The fluctuations are present both with and without blades and for the double lip seal across all purge flow rates. At present, their effect on ingestion is not understood.

Figure 18 shows normalised steady pressures in the cavity and rim seal for the single lip (plot a) and double lip (plot b) seals. Both sets of data have similar purge flow rates, $\Phi$, illustrated by the corresponding point on the effectiveness curves immediately above. The data are plotted against normalised radius. It can be seen that the radial pressure gradient below $r / r_{\mathrm{b}}=0.9$ is similar for both seals. The pressure drop across the seal lip is also similar, but the variation in pressure through the rim seal cavity is different. The magnitude of the unsteady pressure variations in the rim seal and upper cavity is illus-

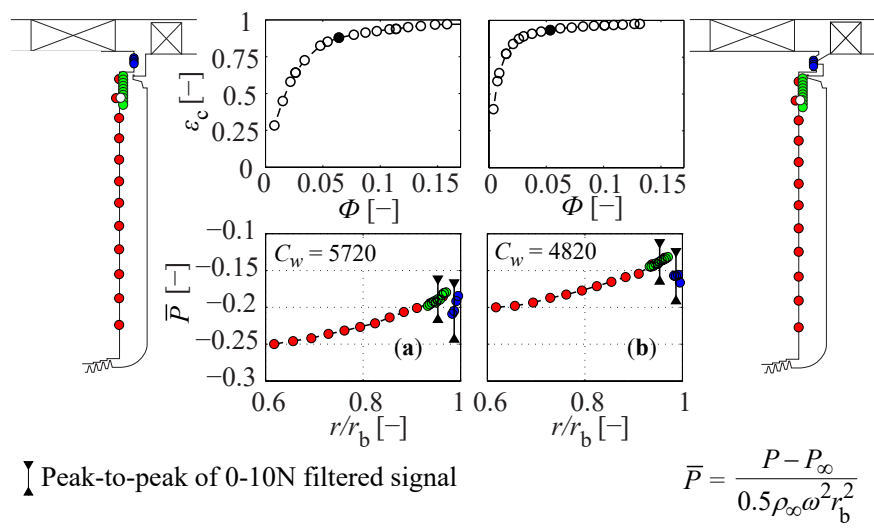

FIGURE 18. Comparison of steady and unsteady pressures for the single lip (a) and double lip (b) seals, $R e_{\theta}=4.9 \times 10^{6}, R e_{x}=2.3 \times 10^{6}$.

trated using the measured peak-to-peak pressure excursions in the frequency range $0-10 N$. The unsteady pressure excursions are greater than the pressure drop across the seal lip, and are likely to contribute to the ingestion of mainstream flow into the cavity.

In an acoustic sense, the test rig can be considered as a series of 9 interconnected volumes. It is highly likely that given the broadband excitation from the shear layer instability, the peaks of some of the frequency content in the spectrograms correspond to acoustic resonances. The same can be said for an engine, although the specific frequencies would be different. However, the lower temperature in the rig gives a similar ratio of sound speed to linear dimensions as the engine.

As introduced in the Background section, very low order coherent structures have been observed in a limited number of computational studies employing full annulus unsteady RANS simulations. In the data presented here, unsteadiness can be seen over a range of different frequencies (e.g. $1 N, 3-5 N$ ) and there is evidence of the fluctuations appearing and disappearing over time scales of the order of multiple disk revolutions. However, there is no evidence of clear-cut behaviour as the aforementioned CFD simulations would suggest. As remarked by O'Mahoney [24], the unsteady features in RANS CFD could be an exaggeration of the flow field, with URANS "locking-in" to a set amount of vortex pairs.

\section{Variation of Mainstream Flow Coefficient}

Off-design flow coefficients are of interest at part load and engine start-up. Moreover, for new engine designs/iterations the target mainstream flow angles (operating point) may change and the sensitivity to small variations in flow coefficient would be of interest to the engine designer. This is explored below.

The lower halves of figs. 19 and 20 present seal effectiveness, $\varepsilon_{\mathrm{c}}$, plots at two locations in the rotor-stator cavity and one in the rim seal across a range of disk speeds for the unbladed configurations of the single and double lip seals. Measurements are presented at two vane exit Mach numbers, $M_{\mathrm{is}}$, (0.20 and 0.64) and for a fixed purge flow. Along the $x$ axis, the disk speed is represented non-dimensionally as the ratio of disk speed, $\omega r_{\mathrm{b}}$, to mainstream flow velocity, $V_{\infty}$. This ratio is related to the mainstream flow angle and directly related to the 

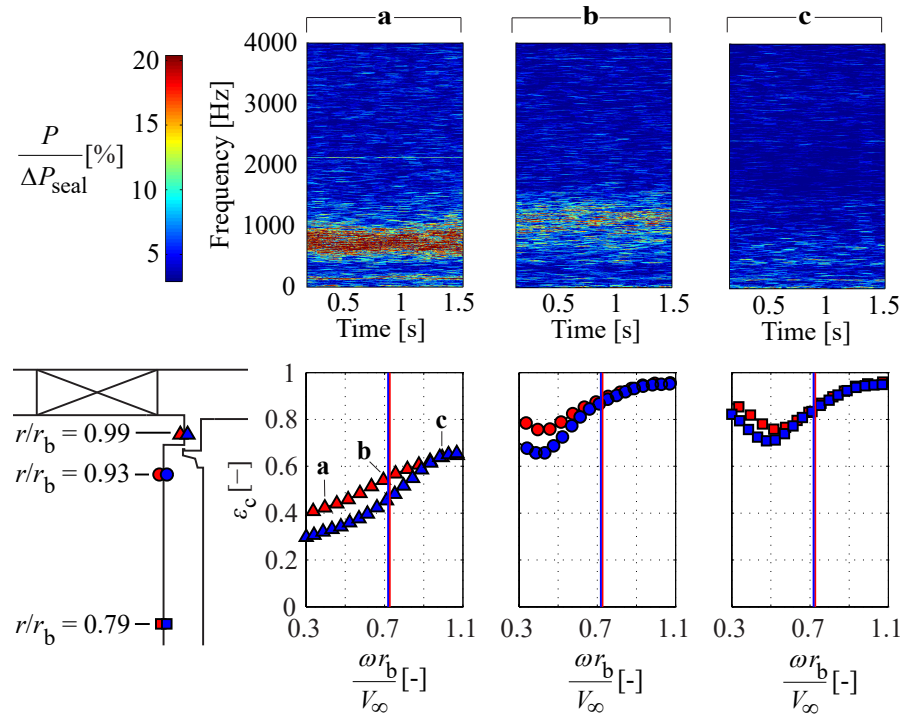

$\Delta$ ○ घ- $M_{\mathrm{is}}=0.64-M_{\mathrm{is}}=0.64, R e_{\theta}=4.9 \times 10^{6}$ purge sweep (engine-matched $\phi$ )

$\Delta \bullet \mathrm{a}-M_{\mathrm{is}}=0.20-M_{\mathrm{is}}=0.20, R e_{\theta}=1.9 \times 10^{6}$ purge sweep (engine-matched $\phi$ )

FIGURE 19. Single lip seal - Top: Spectrograms of unsteady pressure signal in the rim seal cavity at the 3 disk speeds corresponding to (a), (b) and (c). Bottom: Variation in seal effectiveness, $\varepsilon_{\mathrm{c}}$, with disk speed normalised by mainstream velocity at 3 radial locations.

inverse of the mainstream flow coefficient (the vane exit angle is set by the vane geometry and approximately constant so these subsonic vane exit Mach numbers).

From figs. 19 and 20, it can be seen that the trends in seal effectiveness at the two Mach numbers (0.64 and 0.20) follow characteristic curves. In the rim seal cavity, the seal effectiveness decreases with decreasing disk speed. In the rotor-stator cavity, the seal effectiveness also decreases with decreasing speed at first. Past a certain point, a rise in seal effectiveness is observed as the disk speed is further reduced. This rise is attributed to a decrease in the dominance of rotational effects which normally act to resist mixing near the rim seal and to transport ingress radially inwards along the stator.

Figs. 19 and 20 also show spectrograms of the unsteady pressure in the rim seal cavity (at $r / r_{\mathrm{b}}=0.98$ ) corresponding to points $\mathbf{a}, \mathbf{b}, \mathbf{c}$ in the seal effectiveness plots for the $M_{\text {is }}=0.64$ cases. Each spectrogram spans $1.5 \mathrm{~s}$ in time and has a frequency axis between 0 and $4000 \mathrm{~Hz}$ (BPF is at approximately $3.9 \mathrm{kHz}$ for an engine-matched flow coefficient at $\left.M_{\text {is }}=0.64\right)$.

The spectrograms help explain the sealing effectiveness trends observed at different disk speeds (flow coefficients). As the disk speed, $\omega r_{\mathrm{b}}$, is reduced (spectrograms $\mathbf{c}$ to $\mathbf{a}$ ), the band of spectral activity discussed in the preceding sections of this paper, forms, grows in magnitude and decreases in frequency.

The stronger activity at lower disk speeds, $\omega r_{\mathrm{b}}$, (i.e. higher flow coefficient) in figs. 19 and 20 is consistent with the growing mismatch in tangential velocity between the rim seal cavity and mainstream flows at lower disk speeds. With reference to the schematic in fig. 21 , bound on one side by the rotating rim seal (spinning at $\omega r_{\mathrm{b}}$ ) and on the other by the stationary rim seal, the tangential speed of the flow in the rim seal cavity has an intermediate value, $\beta \omega r_{\mathrm{b}}$, where $\beta$ is a scale factor. As the disk
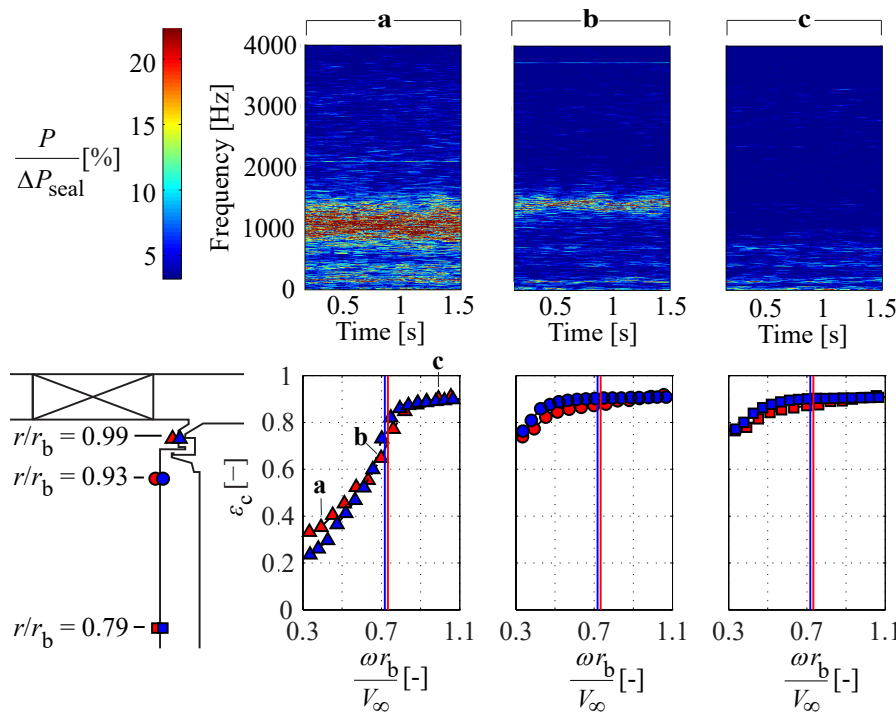

$\Delta \circ \square-M_{\mathrm{is}}=0.64-M_{\mathrm{is}}=0.64, R e_{\theta}=4.9 \times 10^{6}$ purge sweep (engine-matched $\phi$ ) $\Delta \bullet-M_{\mathrm{is}}=0.20-M_{\mathrm{is}}=0.20, R e_{\theta}=1.9 \times 10^{6}$ purge sweep (engine-matched $\phi$ )

FIGURE 20. Double lip seal - Top: Spectrograms of unsteady pressure signal in the rim seal cavity at 3 disk speeds. Bottom: Variation in seal effectiveness, $\varepsilon_{\mathrm{c}}$, with disk speed normalised by mainstream velocity at 3 radial locations.

speed drops (illustrations (a) to (b) in fig. 21), so does the speed of the flow in the rim seal cavity. The mainstream velocity, $V_{\infty}$, remains fixed as the disk speed decreases and $\Delta V_{\theta}$ (the tangential velocity of the mainstream flow relative to the rim seal flow) increases.

Increased activity in the rim seal cavity is indicative of enhanced mixing, which for a constant flow rate of egress from the rotor-stator cavity would mean a lower overall seal effectiveness, $\varepsilon_{\mathrm{c}}$, in the rim seal cavity. In turn, lower $\varepsilon_{\mathrm{c}}$ in the rim seal cavity would lead to an increased difference in $\varepsilon_{\mathrm{c}}$ across the seal lip driving more net ingress into the cavity. This is generally observed to hold true up until the low point in the rotor-stator cavity $\varepsilon_{\mathrm{c}}$ measurements.

The vertical blue and red lines in the seal effectiveness plots in figs. 19 and 20 represent the disk speed at which the low Re condition and high Re condition purge flow sweep effectiveness measurements presented throughout this paper were performed (matched engine flow coefficient). Unlike for the single lip seal, the rotor-stator cavity $\varepsilon_{\mathrm{c}}$ is markedly less sensitive to variations around the engine matched flow coefficient for the double lip seal. For a $10 \%$ decrease in disk speed (11\% increase in flow

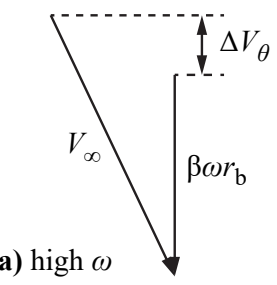

(b) low $\omega$

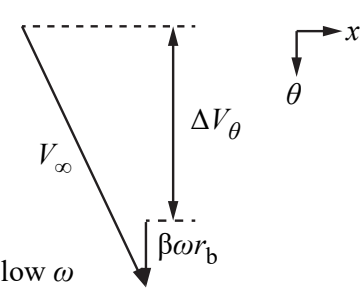

FIGURE 21. Effect of disk speed on relative flow velocity at the rim seal cavity. 
coefficient), the decrease in $\varepsilon_{\mathrm{c}}$ at $r / r_{\mathrm{b}}=0.93$ is approximately $5 \%$ for the single lip seal and nearly an order of magnitude less for the double lip seal. A likely explanation for the reduced sensitivity in the rotor-stator cavity would relate to the longer seal path of the double lip seal relative to the single lip geometry. Stronger fluctuations would be required to force mixing sufficiently far into the rim seal cavity and increase ingress through the lower lip. Unlike in the rotor-stator cavity, the largest sensitivity to flow coefficient in the rim seal cavity is exhibited by the double lip seal. At a mainstream Mach number of 0.64 , a near $24 \%$ drop in $\varepsilon_{\mathrm{c}}$ is measured for a $10 \%$ decrease in disk speed more than double the equivalent single lip seal measurements. This is likely as a result of the reduced flow rate through the seal in the case of the double lip geometry.

The trends in seal effectiveness in figs. 19 and 20, illustrate the importance of featuring engine representative mainstream swirl and replicating the velocity triangles at the rim seal in scaled experiments. More notably, however, the data suggests that although a better seal geometry (such as the double lip seal) would lead to decreased sensitivity to ingestion in the rotor-stator cavity, this would come at the expense of increased sensitivity in the rim seal cavity/at the outer seal lips.

\section{CONCLUSIONS}

The double lip seal performance is significantly better than that of the single lip. Unlike the double lip seal, the single lip seal is shown to be sensitive to the introduction of a simulated engine blade pressure field and overall Reynolds number.

In the case of both seals, unsteady pressure variations attributed to shear layer interaction between the mainstream and rim seal flows appear to be important for ingestion at off-design flow coefficients. At higher than nominal flow coefficients, intensified spectral activity in the rim seal cavity and lower seal effectiveness are measured. This sensitivity indicates that experimental modelling should be performed at an engine-matched flow coefficient and, thus, mainstream flow angles.

The geometry of the double lip seal achieves both greater attenuation of the vane pressure field and a reduced concentration gradient at the lower seal lip. As a result, the double lip seal is less sensitive to changes in shear layer interaction and the effects of large scale non-uniform ingestion in the rotor-stator cavity. However, the reduced flow rate through the double lip seal means that the outer lip has increased sensitivity to shear layer interactions.

Overall, this paper shows that seal performance is driven by both - the vane/blade pressure field and the gradient across the inner lip. The implication is that a more accurate representation of both - the pressure field and the mixing due to shear layer interaction would be necessary for more reliable modelling.

Additionally, this paper demonstrates that the stiffened rotor-stator cavity flow structure transports large scale nonuniform ingress along the stator disk with the potential for local hot-spots in the engine case. The data highlights the importance of $360^{\circ}$ circumferential measurements and characterization in modelling.

\section{ACKNOWLEDGEMENT}

The authors would like to thank MHI for their generous financial support and Mr. Masato Araki and Mr. Yoshiyuki Okabe for their valuable discussions and comments.

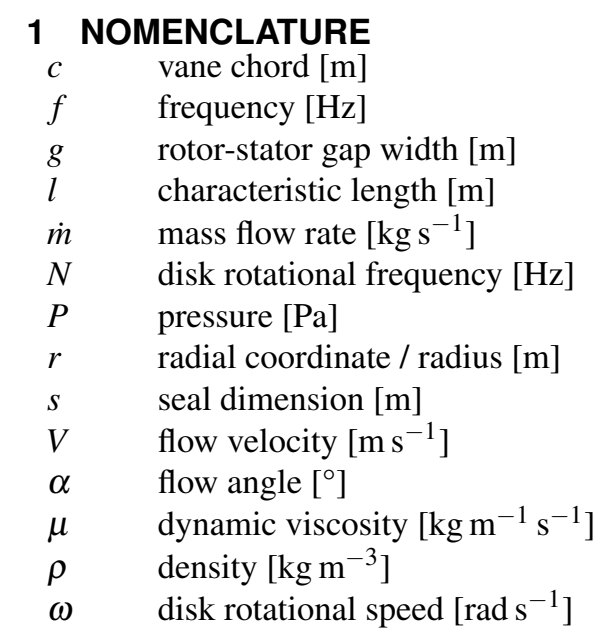

\section{Subscripts}

$\begin{array}{ll}\text { a } & \text { axial distance (rim seal lip to stator) } \\ \mathrm{b} & \text { peripheral rotor radius } \\ \mathrm{c} & \text { rim seal lip clearance, concentration } \\ \text { cav } & \text { rotor-stator cavity } \\ \text { inlet } & \text { inlet condition (vane or blade) } \\ \text { is } & \text { isentropic } \\ \mathrm{n} & \text { at a given measurement point } \\ \mathrm{o} & \text { rim seal lip axial overlap } \\ \text { ptp } & \text { peak-to-peak } \\ \text { purge } & \text { purge flow } \\ \text { rel } & \text { rotor relative frame } \\ \text { seal } & \text { at rim seal lip } \\ x & \text { axial coordinate direction } \\ 0 & \text { stagnation conditions } \\ \theta & \text { tangential coordinate direction } \\ \infty & \text { mainstream conditions at vane exit }\end{array}$

\section{Dimensionless Quantities}

\begin{tabular}{|c|c|c|}
\hline$C_{D}$ & $P-P_{\infty}$ & vane exit pressure coefficient \\
\hline$C P$ & $\begin{array}{c}\overline{P_{0, \text { inlet }}-P_{\infty}} \\
P-P\end{array}$ & valle exit piessuic coentintill \\
\hline$C_{P \text {,rel }}$ & $\frac{\Gamma-T_{\infty}}{P_{0, \text { rel }}-P_{\infty}}$ & $\begin{array}{l}\text { blade relative inlet pressure co- } \\
\text { efficient }\end{array}$ \\
\hline$\overline{\Delta P_{\text {seal }}}$ & $\frac{\Delta P_{\text {seal }}}{0.5 \rho_{\infty} \omega^{2} r_{\mathrm{b}}^{2}}$ & normalized pressure across seal \\
\hline $\bar{P}$ & $\frac{P-P_{\infty}}{0.5 \rho_{\infty} \omega^{2} r_{\mathrm{b}}^{2}}$ & $\begin{array}{l}\text { normalized pressure relative to } \\
\text { disk dynamic head }\end{array}$ \\
\hline$\overline{P_{\mathrm{ptp}}}$ & $\frac{P_{\mathrm{ptp}}}{0.5 \rho_{\infty} \omega^{2} r_{\mathrm{b}}^{2}}$ & $\begin{array}{l}\text { normalized peak-to-peak pres- } \\
\text { sure }\end{array}$ \\
\hline St & $f l / V$ & Strouhal number \\
\hline
\end{tabular}




\begin{tabular}{|c|c|c|}
\hline$C_{w}$ & $\dot{m}_{\text {purge }} /\left(\mu r_{\mathrm{b}}\right)$ & $\begin{array}{l}\text { scale factor of flow tangential } \\
\text { speed relative to local disk speed } \\
\text { dimensionless cooling flow rate }\end{array}$ \\
\hline$M_{\mathrm{is}}\left(\frac{2}{\gamma-}\right.$ & $\left.-1\left[\left(\frac{P_{0}}{P_{\infty}}\right)^{\frac{\gamma-1}{\gamma}}-1\right]\right)^{\frac{1}{2}}$ & isentropic Mach number \\
\hline$R e_{x}$ & $\rho_{\infty} r_{b} V_{\infty} / \mu_{\infty}$ & axial Reynolds number \\
\hline $\operatorname{Re}_{\theta}$ & $\rho_{\infty} \omega r_{\mathrm{b}}^{2} / \mu_{\infty}$ & rotational Reynolds number \\
\hline$\varepsilon_{\mathrm{c}}$ & $\frac{\chi_{\mathrm{n}}-\chi_{\infty}}{\chi_{\text {purge }}-\chi_{\infty}}$ & concentration seal effectiveness \\
\hline$\phi$ & $V_{\infty, x} / \omega r_{\mathrm{b}}$ & mainstream flow coefficient \\
\hline$\Phi$ & $V_{\text {seal }, x} / r_{\text {seal }} \omega$ & sealing parameter \\
\hline$\gamma$ & - & ratio of specific heats \\
\hline $\begin{array}{l}\chi \\
\text { Acronym }\end{array}$ & - & gas concentration by volume \\
\hline BPF & \multicolumn{2}{|c|}{ Blade Passing Frequency } \\
\hline CFD & \multicolumn{2}{|c|}{ Computational Fluid Dynamics } \\
\hline FFT & \multicolumn{2}{|c|}{ Fast Fourier Transform } \\
\hline $\mathrm{K}-\mathrm{H}$ & \multicolumn{2}{|l|}{ Kelvin-Helmholtz } \\
\hline LES & \multicolumn{2}{|c|}{ Large Eddy Simulation } \\
\hline MHI & \multicolumn{2}{|c|}{ Mitsubishi Heavy Industries } \\
\hline NDIR & \multicolumn{2}{|c|}{ Non-dispersive Infra Red } \\
\hline RANS & \multicolumn{2}{|c|}{ Reynolds Averaged Navier-Stokes } \\
\hline URANS & \multicolumn{2}{|c|}{ Unsteady Reynolds Averaged Navier-Stokes } \\
\hline
\end{tabular}

\section{REFERENCES}

[1] Bayley, F. J., and Owen, J. M., 1970. "The fluid dynamics of a shrouded disk system with a radial outflow of coolant". Journal of Engineering for Power, pp. 335-341.

[2] Phadke, U., and Owen, J., 1983. "An investigation of ingress for an "air-cooled" shrouded rotating disk system with radial-clearance seals". Journal of Engineering for Power, 105, pp. 178-183.

[3] Phadke, U., and Owen, J., 1988. "Aerodynamic aspects of the sealing of gas-turbine rotor-stator systems: Part 1: The behavior of simple shrouded rotating-disk systems in a quiescent environment". International Journal of Heat and Fluid Flow, 9(2), pp. 98 - 105.

[4] Bhavnani, S. H., Khodadadi, J. M., Goodling, J. S., and Waggott, J., 1992. "An experimental study of fluid flow in disk cavities". Journal of Turbomachinery, 114(2), pp. 454-461.

[5] T. Abe, J. K., and Takeuchi, H., 1979. "An investigation of turbine disk cooling (experimental investigation and observation of hot gas flow into a wheel space)". 13th International Congress on Combustion Engines.

[6] Phadke, U., and Owen, J., 1988. "Aerodynamic aspects of the sealing of gas-turbine rotor-stator systems: Part 2: The performance of simple seals in a quasi-axisymmetric external flow". International Journal of Heat and Fluid Flow, 9(2), pp. $106-112$.

[7] Phadke, U., and Owen, J., 1988. "Aerodynamic aspects of the sealing of gas-turbine rotor-stator systems: Part 3: The effect of nonaxisymmetric external flow on seal per- formance". International Journal of Heat and Fluid Flow, 9(2), pp. 113 - 117.

[8] Graber, D., Daniels, W., and Johnson, B., 1987. "Disk pumping test". Air Force Wright Aeronautical Laboratories Technical Report(AFWAL-TR-87-2050), September.

[9] Dadkhah, S., Turner, A. B., and Chew, J. W., 1992. "Performance of radial clearance rim seals in upstream and downstream rotor-stator wheelspaces". Journal of Turbomachinery, 114(2), pp. 439-445.

[10] Bohn, D., Johann, E., and Kruger, U., 1995. "Experimental and numerical investigations of aerodynamic aspects of hot gas ingestion in rotor-stator systems with superimposed cooling mass flow". Proceedings of the International Gas Turbine and Aeroengine Congress and Exposition(95-GT-143).

[11] Zhou, D. W., Roy, R. P., Wang, C.-Z., and Glahn, J. A., 2011. "Main gas ingestion in a turbine stage for three rim cavity configurations". Journal of Turbomachinery, 133, July.

[12] Green, T., and Turner, A. B., 1994. "Ingestion into the upstream wheelspace of an axial turbine stage". Journal of Turbomachinery, 116(2), pp. 327-332.

[13] Bohn, D., Rudzinski, B., and Surken, N., 2000. "Experimental and numerical investigation of the influence of rotor blades on hot gas ingestion into the upstream cavity of an axial turbine stage". Proceedings of ASME Turbo Expo 2000(2000-GT-284).

[14] Bohn, D., Rudzinski, B., and Surken, N., 1999. "Influence of rim seal geometry on hot gas ingestion into the upstream cavity of an axial turbine". Proceedings of the International Gas Turbine and Aeroengine Congress and Exposition(99-GT-248).

[15] Gentilhomme, O., Hills, N. J., Turner, A. B., and Chew, J. W., 2003. "Measurement and analysis of ingestion through a turbine rim seal". Journal of Turbomachinery, 125(3), pp. 505-512.

[16] Sangan, C. M., Lalwani, Y., Owen, J. M., and Lock, G. D., 2011. "Experimental measurements of ingestion through turbine rim seals. part 2: Rotationally-induced ingress". Proceedings of ASME Turbo Expo 2011(GT2011-45310), June.

[17] Balasubramanian, J., Pathak, P. S., Thiagarajan, J. K., Singh, P., Roy, R. P., and Mirzamoghadam, A. V., 2015. "Experimental study of ingestion in the rotor-stator disk cavity of a subscale axial turbine stage". ASME Journal of Turbomachinery, 137, September.

[18] Chew, J. W., Green, T., and Turner, A. B., 1994. "Rim sealing of rotor-stator wheelspaces in the presence of external flow". International Gas Turbine and Aeroengine Congress and Exposition(94-GT-126).

[19] Reichert, A. W., and Lieser, D., 1999. "Efficiency of airpurged rotor-stator seals in combustion turbine engines". Proceedings of the International Gas Turbine and Aeroengine Congress and Exposition(99-GT-250).

[20] Bohn, D., and Wolff, M., 2003. "Improved forumlation to determine minimum sealing flow - cw,min - for different sealing configurations". Proceedings of 2003 ASME Turbo Expo: Power for Land, Sea and Air(GT2003-38465). 
[21] Scanlon, T., Wilkes, J., Bohn, D., and Gentilhomme, O., 2004. "A simple method for estimating ingestion of annulus gas into a turbine rotor stator cavity in the presence of external pressure variations". Proceedings of ASME Turbo Expo 2004: Power for Land, Sea and Air.(GT200453097), June.

[22] Johnson, B. V., Jakoby, R., Bohn, D., and Cunat, D., 2009. "A method for estimating the influence of time-dependent vane and blade pressure fields on turbine rim seal ingestion". ASME Journal of Turbomachinery, 131, April.

[23] Owen, J., Pountney, O., and Lock, G., 2012. "Prediction of ingress through turbine rim seals - part 2: Combined ingress". ASME Journal of Turbomachinery, 134, May.

[24] T. O’Mahoney, N. Hills, J. C., and Scanlon, T., 2010. "Large-eddy simulation of rim seal ingestion". Proceedings of ASME Turbo Expo 2010: Power for Land, Sea and Air(GT2010-22962).

[25] Cao, C., Chew, J. W., Millington, P. R., and Hogg, S. I., 2004. "Interaction of rim seal and annulus flows in an axial flow turbine". Journal of Engineering for Gas Turbines and Power, 126(4), pp. 786-793.

[26] Jakoby, R., Zierer, T., Lindblad, K., Larsson, J., deVito, L., Bohn, D., Funcke, J., and Decker, A., 2004. "Numerical simulation of the unsteady flow field in an axial turbine rim seal configuration". Proceedings of ASME Turbo Expo 2004: Power for Land, Sea and Air.(GT200453829), June.

[27] Wang, C.-Z., Mathiyalagan, S. P., Johnson, B. V., Glahn, J. A., and Cloud, D. F., 2012. "Rim seal ingestion in a turbine stage from 360-degree time-dependent numerical simulations". Proceedings of ASME Turbo Expo 2012(GT2012-68193).

[28] Mirzamoghadam, A. V., Kanjiyani, S., Riahi, A., Vishnumolakala, R., and Gundeti, L., 2015. "Unsteady 360 computational fluid dynamics validation of a turbine stage mainstream/disk cavity interaction". Journal of Turbomachinery, 137, January.

[29] Roy, R. P., Feng, J., Narzary, D., and Paolillo, R. E., 2005. "Experiment on gas ingestion through axial-flow turbine rim seals". Journal of Engineering for Gas Turbines and Power, 127(3), pp. 573-582.

[30] J. Boudet, N. H., and Chew, J., 2006. "Numerical simulation of the flow interaction between turbine main annulus and disc cavities". Proceedings of ASME Turbo Expo 2006: Power for Land, Sea and Air.(GT2006-90307).

[31] Chilla, M., Hodson, H., and Newman, D., 2013. "Unsteady interaction between annulus and turbine rim seal flows". Journal of Turbomachinery, 135.

[32] Rabs, M., Benra, F., Dohmen, H., and Schneider, O., 2009. "Investigation of flow instabilities near the rim cavity of a 1.5 stage gas turbine". Proceedings of ASME Turbo Expo 2009: Power for Land, Sea and Air(GT2009-59965).

[33] Popovic, I., and Hodson, H. P., 2012. "The effects of a parametric variation of the rim seal geometry on the interaction between hub leakage and mainstream flows in hp turbines". ASME Conference Proceedings(GT201268025).

[34] Popovic, I., and Hodson, H. P., 2012. "Improving turbine stage efficiency and sealing effectiveness through modifications of the rim seal geometry". ASME Conference Proceedings(GT2012-68026).

[35] Mirzamoghadam, A. V., Giebert, D., Molla-Hosseini, K., and Bedrosyan, L., 2012. "The influence of hpt forward disc cavity platform axial oveover geometry on mainstream ingestion". Proceedings of ASME Turbo Expo 2012(GT2012-68429).

[36] Lowry, S. A., and Keeton, L. W., 1987. "Space shuttle main engine high pressure fuel pump aft platform seal cavity flow analysis". NASA Technical Paper 2685, January.

[37] Guo, Z., Rhode, D. L., and Davis, F. M., 1996. "Computed eccentricity effects on turbine rim seals at engine conditions with a mainstream". Journal of Turbomachinery, 118(1), pp. 143-152.

[38] Brandvik, T., and Pullan, G., 2011. "An accelerated 3d navier-stokes solver for flows in turbomachines". Journal of Turbomachinery, 133(2), p. 021025.

[39] Savov, S., 2015. "An experimental investigation of gas turbine rotor-stator cavity purge flow". PhD thesis, University of Cambridge.

[40] Sangan, C. M., Lalwani, Y., Owen, J. M., and Lock, G. D., 2012. "Experimental measurements of ingestion through turbine rim seals. part 3: Single and double seals". Proceedings of ASME Turbo Expo 2012(GT2012-68493), June.

[41] Scobie, J. A., Teuber, R., Li, Y. S., Sangan, C. M., Wilson, M., and Lock, G. D., 2015. "Design of an improved turbine rim-seal". Proceedings of ASME Turbo Expo 2015: Turbine Technical Conference and Exposition(GT201542327), June.

[42] Okita, Y., Nishiura, M., Yamawaki, S., and Hironaka, Y., 2005. "A novel cooling method for turbine rotor-stator rim cavities affected by mainstream ingress". Journal of Engineering for Gas Turbines and Power, 127(4), pp. 798-806.

[43] Sangan, C. M., Scobie, J. A., Owen, J. M., Lock, G. D., Tham, K. M., and Laurello, V. P., 2014. "Performance of a finned turbine rim seal". Proceedings of ASME Turbo Expo 2014: Turbine Technical Conference and Expositions(GT2014-25626), June.

[44] ISO/IEC, 2009. "Guide 98-1:2009 uncertainty of measurement - part 1: Introduction to the expression of uncertainty in measurement.".

[45] Sangan, C. M., Lalwani, Y., Owen, J. M., and Lock, G. D., 2013. "Experimental measurements of ingestion through turbine rim seals. part 5: Fluid dynamics of wheel-space". Proceedings of ASME Turbo Expo 2013: Turbine Technical Conference and Expositions(GT2013-94148), June. 